\title{
PARAMETRIC ANALYSIS OF THERMAL PERFORMANCE OF RANQUE-HILSCH VORTEX TUBE
}

\author{
Kiran Devade ${ }^{1, *}$, Ashok Pise $^{2}$
}

\section{ABSTRACT}

Vortex tube separates pressurized fluid into hot and cold fluid streams simultaneously. Geometrical and operational parameters affect this separation. The study deals with experimental investigations of effect of geometrical and operational parameters. L/D ratio $(15,16,17$ and 18), number of nozzles $(2,4$ and 6$)$, nozzle geometry (straight and Spiral), divergence angle (0, 2, 3, 4 and 5), valve angles (30 to $90 \mathrm{deg}$. in steps of $15 \mathrm{deg}$.) and cold orifice diameter $(5,6$ and $7 \mathrm{~mm})$ are variables. For all the experiments, air is working fluid. Airflows at different pressures ranging from ( 200 to $600 \mathrm{kPa}$ in steps of $100 \mathrm{kPa}$ ).CMF variation is in the range from 0 to 1 for all geometries. The effects on energy separation were analyzed with respect to CMF and Mach number. The results are expressed in percentage rise and drop. Similarity relation is developed and results are compared with literature.

Keywords: Vortex Tube, Energy Separation, Cold Mass Fraction, Stagnation Point, L/D Ratio, Cold Orifice Diameter

\section{INTRODUCTION}

Vortex tube produces hot and cold streams of air from tangentially supplied compressed air. It is one of the non-conventional refrigeration devices. Ranque G.J. [1] invented the vortex tube. The tube being inefficient it was unnoticed until Hilsch [2] started working on enhancing efficiency of the tube. After invention, Ranque's explanation to the vortex effect was criticised. [3, 4] The investigations took momentum following Hilsch work. The tube hence is widely known as RHVT (Ranque-Hilsch Vortex Tube). The device is simple in construction and consists of inlet nozzle/s, vortex chamber, vortex generator, hot tube with valve, cold tube containing orifice. Figure 1 shows the general construction of the tube and Figure2 shows the flow pattern inside the vortex tube.

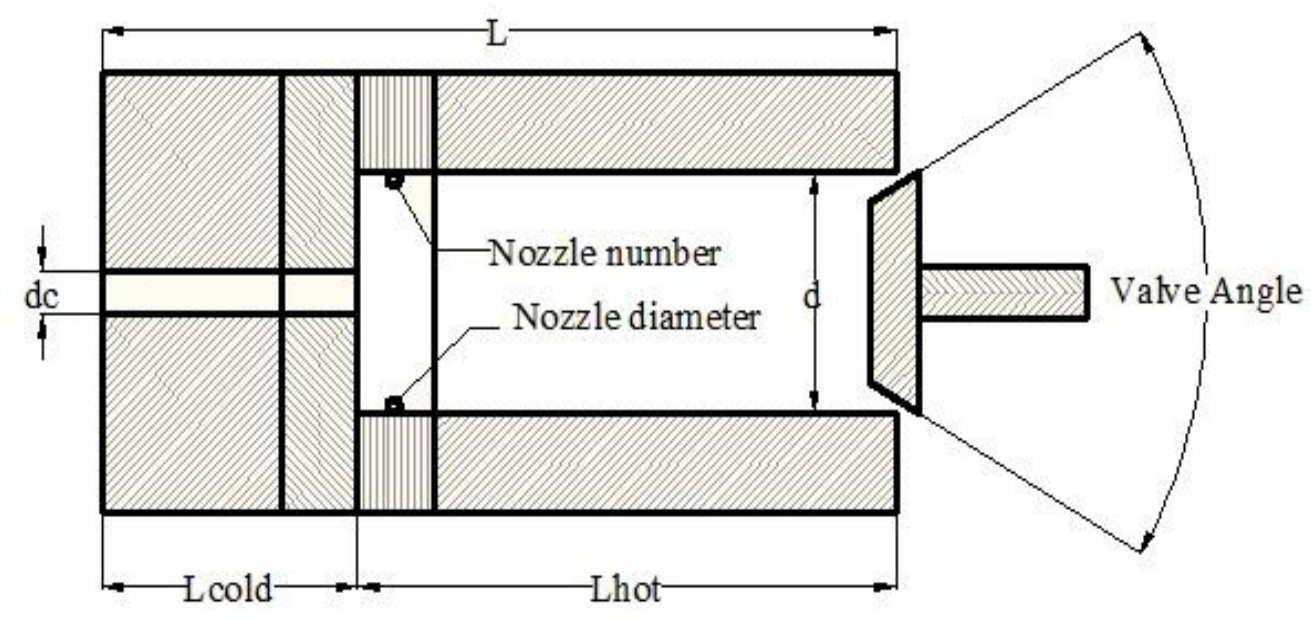

Figure 1. Geometry of the vortex tube

The important terms frequently used in view of vortex tube are as follows,

\section{Cold Mass Fraction}

It is the ratio of cold mass of air to the total mass of air supplied at inlet. It is commonly termed as cold fraction, cold mass fraction, or as coefficient of energy separation. 


$$
C M F=m_{c} / m_{a}
$$

\section{Temperature Difference}

It is the difference between the temperature at hot outlet and temperature at cold outlet. Eguation 2 Difference between inlet temperature and cold end temperature is cold end temperature drop. Eguation 3 Difference between hot end temperature and inlet temperature is hot end temperature rise. Eguation 4

$$
\begin{gathered}
\Delta t=t_{h}-t_{c} \\
\Delta t_{c}=t_{a}-t_{c} \\
\Delta t_{h}=t_{h}-t_{a}
\end{gathered}
$$

\section{Stagnation Point}

This is the point at which core stream reverses its direction, and starts moving from hot end to cold end. Beyond this point, there is no energy separation phenomenon. This is the point at which axial flow velocity component is zero.

\section{Core and Peripheral Stream}

The separated flow in vortex tube has two elements, the hot flow that occurs at periphery is termed as peripheral stream and the cold flow near tube axis is core stream.

\section{Coefficient of Performance}

Coefficient of performance is the ratio of refrigeration effect to the work required in supplying compressed air.

$$
C O P=\frac{R E}{\text { Compressor Work }}
$$

These are common terms used in performance analysis of vortex tube.

\section{PRINCIPLE OF OPERATION}

The working principle of vortex tube is complex in nature. Many theories discuss the mechanism of separation. The mechanism of the working of the vortex tube is as follows. Compressed air enters tangentially inside the tube through the nozzle as shown in Figure2. At entry, the air expands and attains high velocity. Air travels in a spiral like motion along the periphery of the tube. The valve at the hot end of the tube restricts this swirling flow and the pressure near the exit valve increases slightly. With the valve closure, the flow becomes stagnant and kinetic energy of the flow converts into heat energy. On the axis, this stagnant flow locates stagnation point, which contributes to the energy separation by virtue of its position.

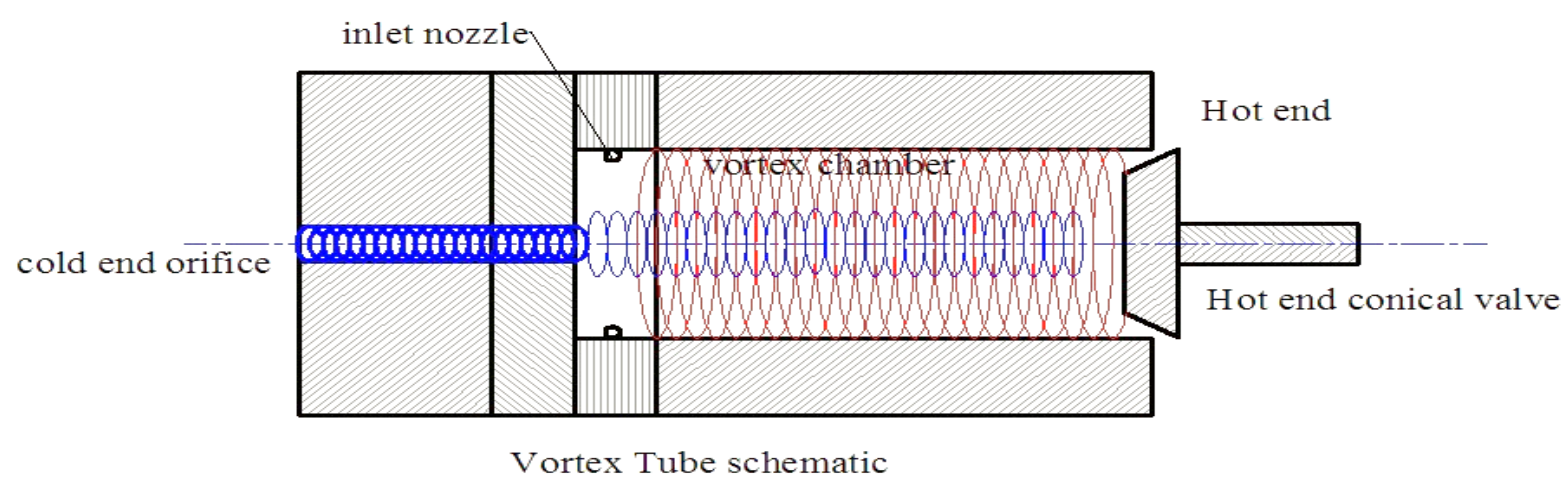

Figure 2. General flow patterns in vortex tube 
The flow of air reverses from slightly high-pressure region created at the hot end of the low-pressure region at entry. The reversed stream flows through the core of the tube. Peripheral high velocity flow surrounds or encompasses the reversed flow stream. The peripheral stream makes the central layer to rotate, thus central layer gains rotation at the expense of heat. This causes heat transfer to take place between reversed core stream and peripheral stream. Therefore, air stream passing through the core, is cooled below the inlet temperature of the air in the vortex tube, while the air stream in forward direction is heated. The cold and hot stream emerging out simultaneously has derived attention of many researchers. This separation of streams is also known as thermal separation, energy separation, or vortex effect. Variation of geometrical and operational parameters has significant effect on energy separation.

The energy separation is dependent on geometrical and operational parameters. The experiments performed by scientific community are in wide range and the results are contradictory. Based on gap analysis, effect of geometrical and operational parameters was undertaken in selected range. Figure 4 shows the images of all the geometry variations used for experimentation. $\mathrm{L} / \mathrm{D}$ ratio $\left(15,16,17\right.$ and 18), number of nozzles $\left(\mathrm{N}_{\mathrm{n}}\right)(2,4$ and 6), nozzle geometry (straight and Spiral), divergence angle $(\phi)(0,2,3,4$ and 5), hot end valve angles $(\Theta)(30$ to $90 \mathrm{deg}$. in steps of $15 \mathrm{deg}$.) and cold orifice diameter $\left(\mathrm{d}_{\mathrm{o}}\right)(5,6 \mathrm{and} 7 \mathrm{~mm})$ are variables. For all the experiments, air is working fluid. Air at entry, is supplied at different pressures $\left(\mathrm{P}_{\mathrm{i}}\right)$ ranging from $(200$ to $600 \mathrm{KPa}$ in steps of $100 \mathrm{KPa}$ ). CMF variation is in the range from 0 to 1 for all geometries. The results of the researchers are mentioned in every part of concerned discussion.

The study differs from literature in discussing the effect of all geometrical parameters on COP and energy separation. The effect of cold mass fraction and Mach number is considered on the COP and energy separation this is the significant novelty of the experimental work.

\section{EXPERIMENTAL SETUP}

The experimental setup developed for the study is as shown in Figure 3 the components of the setup are air compressor with pressure regulator (1) for pressurized air supply, Rotameter $(2,4)$ at inlet and cold outlet for measurement of mass of cold and hot air streams with $\pm 11 \mathrm{pm}$ accuracy. Vortex tube (3) has a provision for replacement of cold end orifice, nozzles and exit valves. For temperature measurement K-type, thermocouples (5) are used at the inlet, cold and hot end outlets for with accuracy of $\pm 0.1^{\circ} \mathrm{C}$.All temperatures are recorded using digital indicator (6) with accuracy of $\pm 0.1^{\circ} \mathrm{C}$. For experiments, pressure at the inlet of the vortex tube is varied from 200 to $600 \mathrm{kPa}$. Bourdon pressure gauge is used for pressure measurement having accuracy of $\pm 10 \mathrm{KPa}$. Constant inlet pressure is maintained using a pressure regulator in steps of $100 \mathrm{kPa}$. The velocity at the inlet of the tube is measured using single probe hot wire anemometer having accuracy of $\pm 0.1 \mathrm{msec}^{-1}$.

1. Air Compressor

2. Inlet air Rotameter

3. Vortex Tube

4. Cold air Rotameter

5. Thermocouples

6. Temperature Indicator

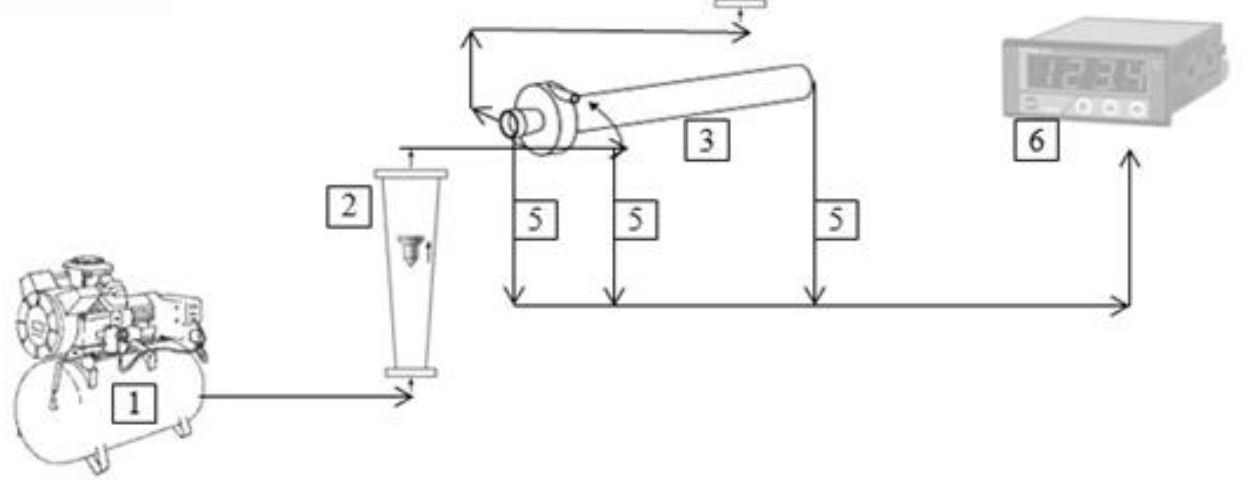

Figure 3. Schematic of experimental test rig 


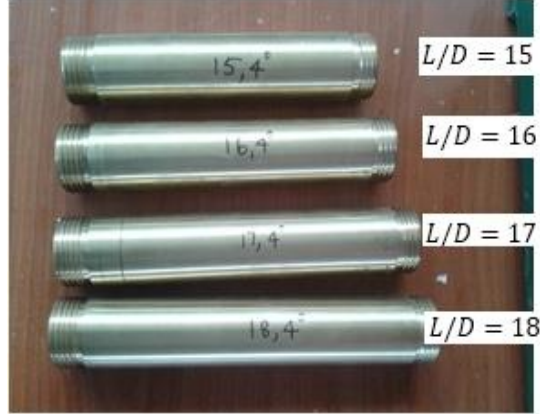

(a) Tubes of Different $\mathrm{L} / \mathrm{D}$ ratios Used

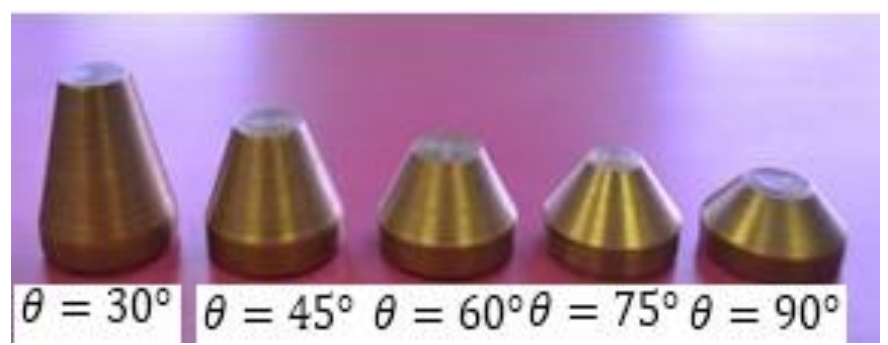

(c) Hot end valves of different angles

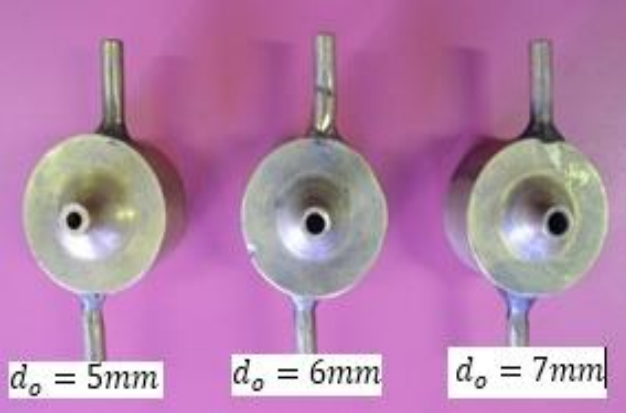

(b) Different Cold end orifice diameters

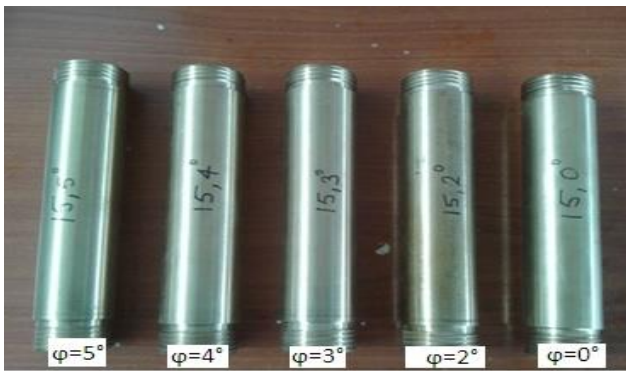

(d) Tubes of varying divergence angle
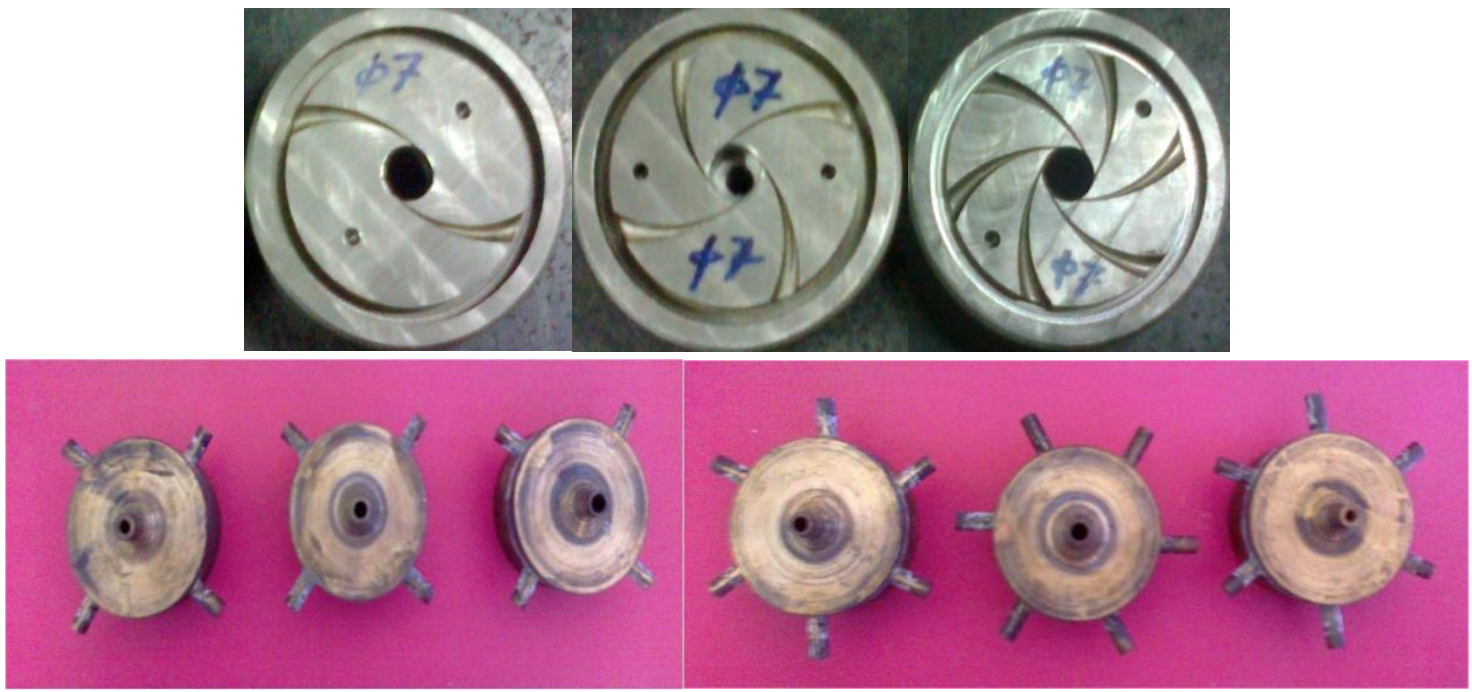

(e) Various nozzle and nozzle shapes used

Figure 4. Various geometries used for experimentation

\section{DATA REDUCTION}

Data obtained from the experiment was used for estimating performance parameters. Various performance analysis parameters are listed below,

$$
\begin{gathered}
C M F=\frac{m_{c}}{m_{i}} \\
C O P_{a c t}=\frac{R_{E}}{W_{c o m p}} \\
R_{E}=m_{c} c_{p}\left(t_{i}-t_{c}\right. \\
W_{\text {comp }}=m_{i} R t_{i} \ln \frac{p_{d}}{p_{i}}
\end{gathered}
$$




$$
\begin{gathered}
\Delta t_{c}=t_{i}-t_{c} \\
\Delta t_{c}^{\prime}=t_{i}\left[1-\left(\frac{p_{d}}{p_{i}}\right)^{\frac{\gamma-1}{\gamma}}\right] \\
\Delta t_{r e l}=\frac{\Delta t_{c}}{\Delta t_{c}^{\prime}} \\
\eta_{a d}=C M F\left(\Delta t_{r e l}\right) \\
\eta_{c o m p}=\frac{\ln \frac{p_{d}}{p_{i}}}{\frac{\gamma}{\gamma-1}\left[\left(\frac{p_{d}}{p_{i}}\right)^{\frac{\gamma-1}{\gamma}}-1\right]} \\
\operatorname{COP}_{t h}=\eta_{a d} \eta_{c o m p}\left(\frac{p_{d}}{p_{i}}\right)^{\frac{(\gamma-1)}{\gamma}} \\
M_{a}=\frac{V_{i}}{\sqrt{\gamma R T}}
\end{gathered}
$$

Uncertainty analysis was carried out with measured parameters and calculated parameters like COP, CMF and $\Delta \mathrm{T}_{\mathrm{c}}$. The uncertainty of measured parameters is $\pm 1.8 \%$ and average uncertainty for calculated parameters it is $\pm 4.2 \%$.

\section{RESULTS AND DISCUSSIONS}

The effect of geometrical parameters like length to diameter ratio $(\mathrm{L} / \mathrm{D})$, exit valve angle $(\Theta)$, tube divergence angle $(\phi)$, Number of nozzles $\left(\mathrm{N}_{\mathrm{n}}\right)$, shape of nozzle and cold end orifice diameter $\left(\mathrm{d}_{\mathrm{o}}\right)$ was analysed on $\mathrm{COP}$ and $\Delta \mathrm{T}_{\mathrm{c}}$. All these results are analysed with variation of cold mass fraction (CMF) and Mach number $\left(\mathrm{M}_{\mathrm{a}}\right)$ at the inlet of vortex tube. The results are presented along with the related literature and the results obtained during the experiments. Correlations are developed for optimum performance of the geometry parameters and are stated in every part of discussion, the general form of the correlation equation is,

$$
C M F_{\text {opt }} / C O P_{\text {opt }} /\left(\frac{\Delta T_{c}}{\Delta T_{\text {cmax }}}\right)_{o p t}=+p(z)^{3}+q(z)^{2}+r(z)+s
$$

In this correlation, $\mathrm{z}$ is the dimensionless geometry parameter and $\mathrm{p}, \mathrm{q}, \mathrm{r}$ and $\mathrm{s}$ are coefficients of equation. The values of all the coefficients related to Eguation 17 for optimum performance are listed in Table 2.

\section{L/D Ratio}

$\mathrm{L} / \mathrm{D}$ ratio is the ratio of length of vortex tube to diameter. The length and diameter individually affect the performance of vortex tube. Hence, a combined parameter is usually referred as $\mathrm{L} /$ Dratio, which presents combined effect on performance. The range of L/D ratios used is from 1 to 800 and most of the researchers have used L/D ratio is in the range of 10 to 20 . Gulyaev [5] suggested that $L / D>13$ is best for increasing energy separation of diverging tubes. Aydin [6] based on the experimental results suggested that $\mathrm{L} / \mathrm{D} \approx 20$ for attaining optimum results. Saidi and Valipour [7] optimized L/D ratio for best efficiency, and suggested that for achieving higher efficiency, $\mathrm{L} / \mathrm{D}$ ratio should be in the range of $20 \leq L / D \leq 55.5$. Cockerill [8] experimentally analyzed the correlations for 
all geometry parameters have been developed in the form of, $C M F_{o p t} / C O P_{o p t} /\left(\frac{\Delta T_{C}}{\Delta T_{c m a x}}\right)_{o p t}= \pm p(z)^{3} \pm$ $q(z)^{2} \pm r(z) \pm s$, the correlation coefficients for all the developed equations are as follows, $\mathrm{p}, \mathrm{q}, \mathrm{r}$ and $\mathrm{s}$ are coefficients and $\mathrm{Z}$ is the Non dimensional geometry parameter.

$\mathrm{L} / \mathrm{D}$ ratio is equal to 60 and 64 for effective temperature separation. Piralishvili [9] reported that the kinetic energy losses are minimized with lower L/D ratios (1-12). Saidi et al. in [10] another analysis has shown that exergy destruction decreases and temperature difference increases, with increase of L/D. Markal et al. noticed [11] that smaller L/D ratio deteriorate performance because of mixing of the cold and hot streams. Researchers have used wide range of L/D ratio, for obtaining behavior of vortex tube a close range needs attention; hence a close range was selected for study.

In this view, for present study L/D ratio was varied from 15 to 18 , all these tubes have fixed $4^{0}$-divergence angle. One tube with $\mathrm{L} / \mathrm{D}$ ratio equal to 15 and $\phi$ equal to $0^{0}$ was used for comparison of results as against straight tube.

\section{Effect of CMF}

The results of effect of L/D ratio on temperature separation and COP are as shown in Figure 5 and Figure 6. It is seen that $\mathrm{L} / \mathrm{D}$ equal to 17 with $\varnothing$ equal to $4^{0}$ has produced maximum COP of 0.077 at $\mathrm{CMF}$ equal to 0.78 and $\Delta \mathrm{T}_{\mathrm{c}} / \Delta \mathrm{T}_{\mathrm{cmax}}$ equal to 0.8 . This is the optimum performance of the tube. Optimum performance values are extracted from the intersecting points of $\Delta \mathrm{T}_{\mathrm{c}} / \Delta \mathrm{T}_{\mathrm{cmax}}$ and COP for each L/D. It is observed that with increase in $\mathrm{L} / \mathrm{D}$ ratio the performance increase up to certain length and again it starts declining i.e. for L/D ratio from 15 to 17 there is increase in performance and at 18, the performance declines. At lower CMF as seen in Figure 5 the tube shows slight heating effect, negative values of COP are obtained when the temperature of stream coming out of cold orifice is higher than that at inlet. At lower CMF for straight tube, hot stream is observed on both ends. The heating is may be because at lower CMF, the flow escapes out through hot end and at the hot end, the core and peripheral stream undergoes mixing and vortex tube acts as a heating device. This may be because of movement to stagnation point near to cold end. The correlation developed for optimum performance in the tested range for $\Delta \mathrm{T}_{\mathrm{c}} / \Delta \mathrm{T}_{\mathrm{cmax}}, \mathrm{COP}$ and $\mathrm{CMF}$ are as follows, the values mentioned above are for optimum performance. The correlations are as given in Table 1.

For a fixed tube diameter, as length of tube increase there is increase in performance from 15 to 17 for all parameters and at 18, the lower trend starts. The probable reason is that with initial increase in L/D ratio, stagnation point may shift towards hot end increasing the energy separation zone but with further increase in length, may displace the position of stagnation point towards cold end thus affecting the energy separation zone. It was observed that with increase in L/D ratio, percentage increase in COP is $31 \%$ up to L/D equal to 17 and then at 18 , COP drops by $20 \%$. The similar findings were reported by $[12,13]$, that performance enhances with increase of $\mathrm{L} / \mathrm{D}$ ratio up to certain limit then it decreases. The obtained results are in agreement with the literature. COP profile for L/D 16 and 17 is constant with less significant influence of CMF, in all other L/D ratios the performance varies with CMF. For L/D 18 it increases with CMF up to 0.5 and then declines. Overall, COP increases with increase in $\mathrm{CMF}$, irrespective of $\mathrm{L} / \mathrm{D}$ ratio.

Similarly, temperature separation is also CMF dependent and it can be seen that maximum temperature separation occurs at CMF equal to 0.45 and the corresponding value is 1 . It is followed that as CMF increases the flow field might be disturbed and energy separation is reduced. The obtained results are in the range of L/D equal to 15 to 18 for diverging tube; this enhancement in the result is in contrast to Bramo and Pourmahmoud [14] as they obtained reduction in performance for L/D in between 10 to 30 . 
Table 1. Coefficients of correlations and regression coefficient

\begin{tabular}{|c|c|c|c|c|c|c|}
\hline $\mathbf{Z}$ & & p & $\mathbf{q}$ & $\mathbf{r}$ & $\mathbf{s}$ & $\mathbf{R}^{2}$ \\
\hline \multirow{5}{*}{$\frac{L}{D}$} & $C M F_{\text {opt }}$ & -0.967 & 4.625 & -73.368 & 386.5 & 1 \\
\hline & $C O P_{\text {opt }}$ & -0.0017 & 0.0787 & -1.20129 & 6.118 & 1 \\
\hline & $\left(\Delta T_{c}\right)$ & & & & & \\
\hline & $\left(\overline{\Delta T_{\text {cmax }}}\right)_{\text {opt }}$ & -0.025 & 1.17 & -18.135 & 93.79 & 1 \\
\hline & $C M F_{o p t}$ & 0.0 & 0.0388 & -0.3225 & 1.49 & 1 \\
\hline \multirow{4}{*}{$\underset{\quad \text { Entry }}{N_{n} \text { Straight }}$} & $C O P_{\text {opt }}$ & 0.0 & 0.0119 & -0.1088 & 0.505 & 1 \\
\hline & $\left(\Delta T_{c}\right)$ & & & & & \\
\hline & $\left(\overline{\Delta T_{\text {cmax }}}\right)_{o p t}$ & 0.0 & 0.0225 & -0.185 & 1.28 & 1 \\
\hline & $C M F_{o p t}$ & 0.0 & -0.0112 & 0.1775 & 0.29 & 1 \\
\hline \multirow{4}{*}{$N_{n}$ Spiral Entry } & $C O P_{o p t}$ & 0.0 & 0.0148 & -0.07 & 0.169 & 1 \\
\hline & $\left(\Delta T_{c}\right)$ & & & & & \\
\hline & $\left(\overline{\Delta T_{\text {cmax }}}\right)_{o p t}$ & 0.0 & 0.0375 & -0.25 & 1 & 1 \\
\hline & $C M F_{o p t}$ & -0.0315 & -0.2116 & 0.3954 & 0.2149 & 0.57 \\
\hline$\varnothing$ & $C O P_{\text {opt }}$ & -0.0006 & -0.0041 & 0.0045 & 0.0373 & 0.81 \\
\hline \multirow[t]{3}{*}{$\overline{\emptyset_{\max }}$} & $\Delta T_{c}$ & & & & & \\
\hline & $\left(\overline{\Delta T_{\text {cmax }}}\right)_{o p t}$ & -0.0323 & 0.2436 & -0.3435 & 0.4601 & 1 \\
\hline & $C M F_{\text {opt }}$ & $3 e^{-5}$ & -0.0052 & 0.2999 & -4.784 & 0.82 \\
\hline $\boldsymbol{\theta}$ & $C O P_{\text {opt }}$ & $6 e^{-7}$ & -0.0001 & 0.0074 & -0.0718 & 0.99 \\
\hline \multirow[t]{2}{*}{$\overline{\theta_{\max }}$} & $\Delta T_{c}$ & & & & & \\
\hline & $\left(\overline{\Delta T_{\text {cmax }}}\right)_{\text {opt }}$ & $-9 e^{-6}$ & 0.0017 & -0.0921 & 2.204 & 0.95 \\
\hline
\end{tabular}

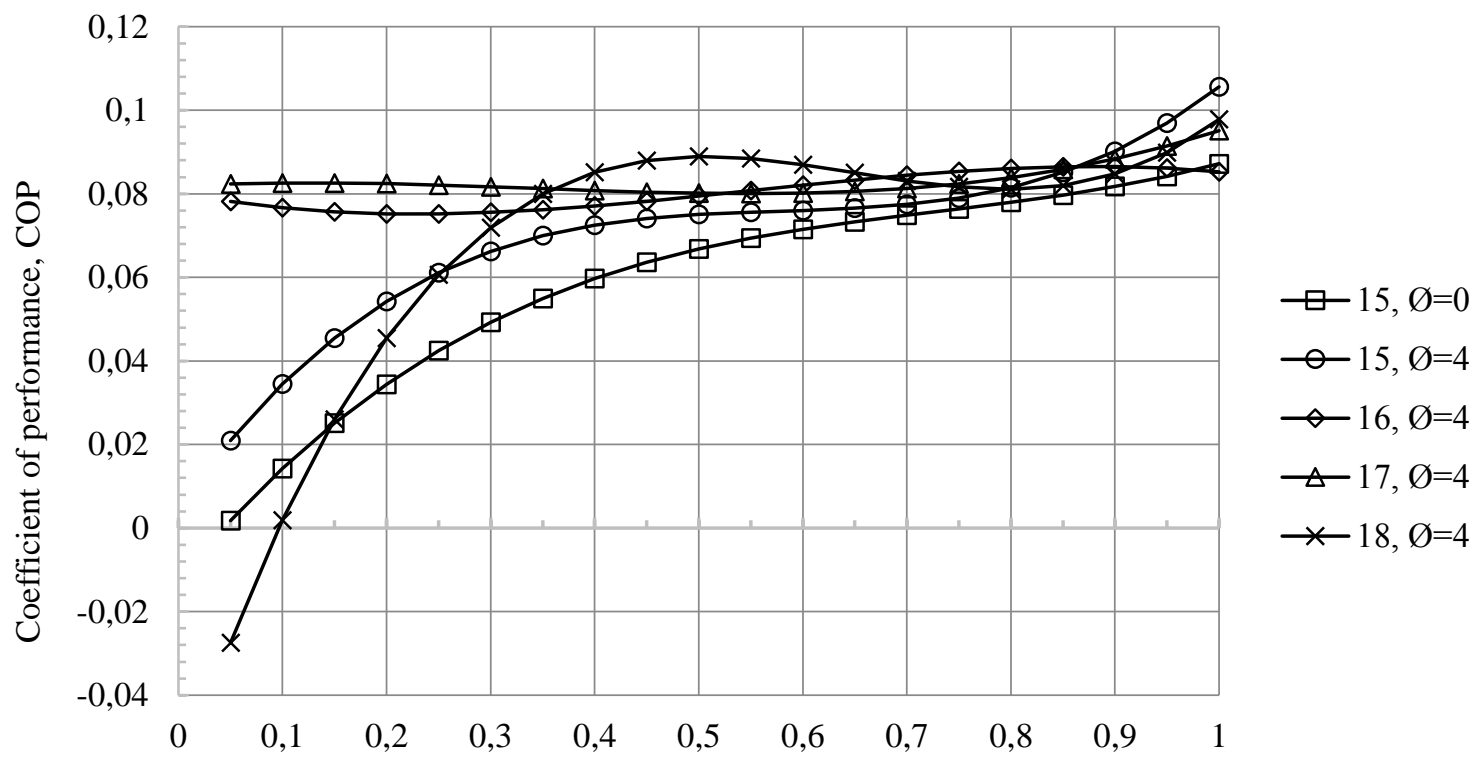

Cold mass fraction, COP

Figure 5. Effects of L/D and CMF on COP 


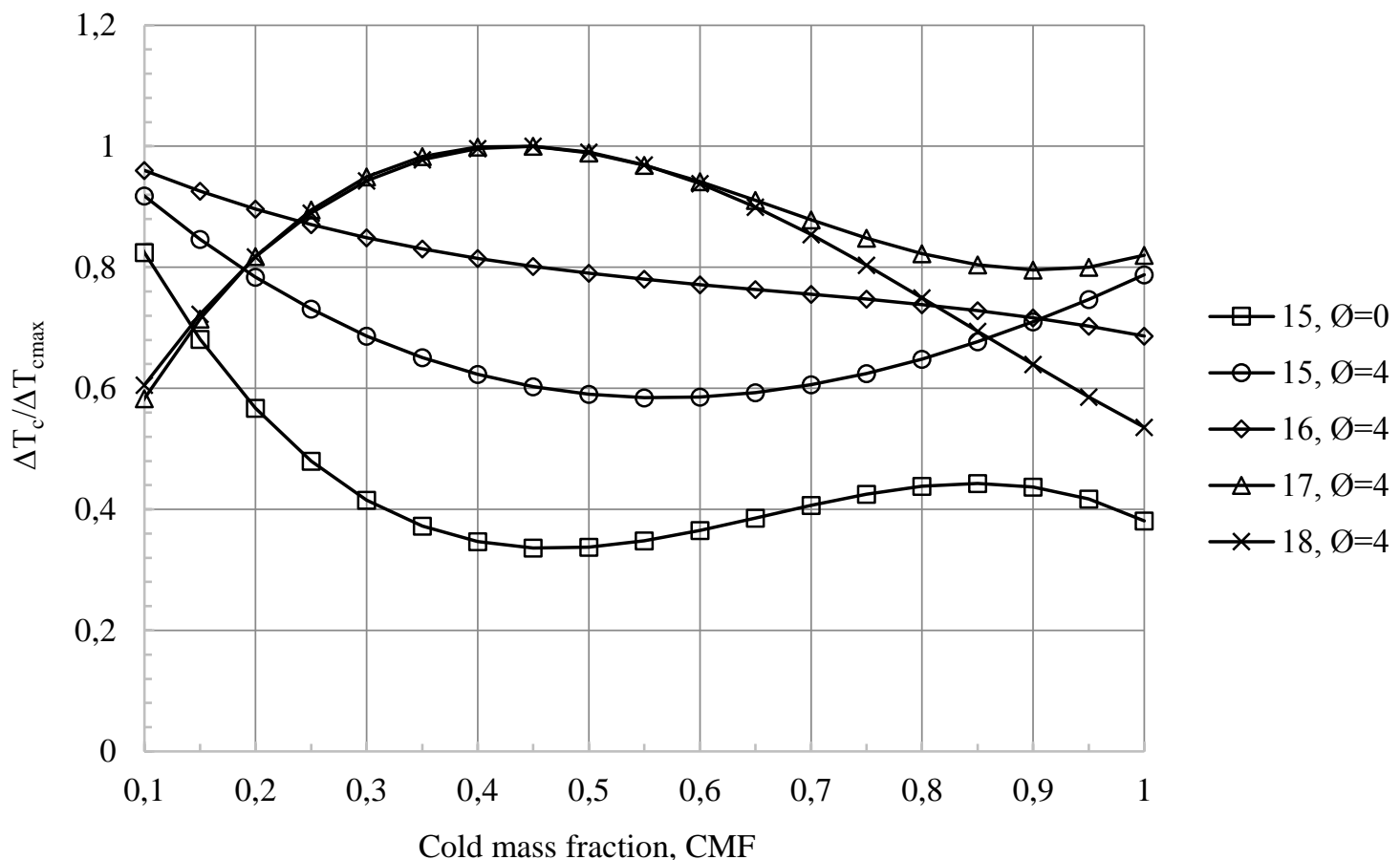

Figure 6. Effects of L/D and CMF on Temperature Separation

\section{Effect of Mach Number}

Effect of Mach number on COP and temperature separation can be seen in Figure 7 and 8. It is seen that within the subsonic limits all L/D ratios perform equally same and at supersonic Mach numbers large deviations occur. Straight tube of L/D equal to 15 and divergent tube of L/D equal to17-show rise in performance at supersonic Mach numbers. The large deviation in performance is attributed to the rise of velocities at inlet. High velocities at inlet lead to increased turbulence and mixing of the two streams. The mixing of the streams reduces the energy separation. Energy separation in diverging tubes with L/D equal to 15 is $53 \%$ higher than straight tube of L/D equal to 15 . While the performance of $\mathrm{L} / \mathrm{D}$ equal to 16 and 17 is $38 \%$ higher than straight tube of $\mathrm{L} / \mathrm{D}$ equal to 15 .

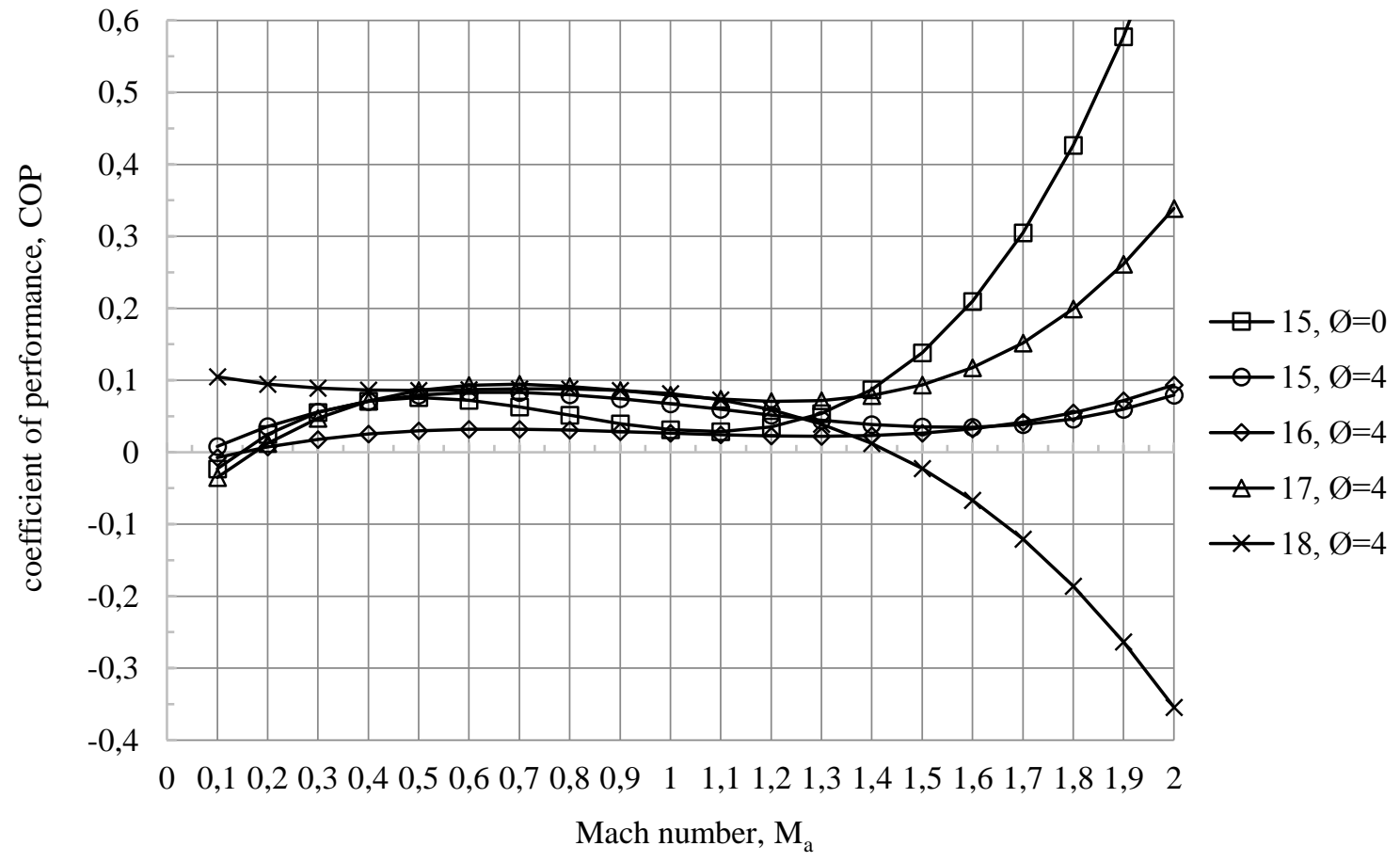

Figure 7. Effects of $\mathrm{L} / \mathrm{D}$ and $\mathrm{M}_{\mathrm{a}}$ on COP 
Straight tubes perform better providing increased COP, at higher Mach number compared to diverging tubes this may be because of in velocity decelerations in diverging tube. The gradual increase in cross section decelerates the flow reducing swirl intensity. Diverging tubes of L/D 15 and 18 provides high temperature separation at sonic Mach numbers. Performance for COP of straight tubes is $68 \%$ higher than average performance of diverging tubes.

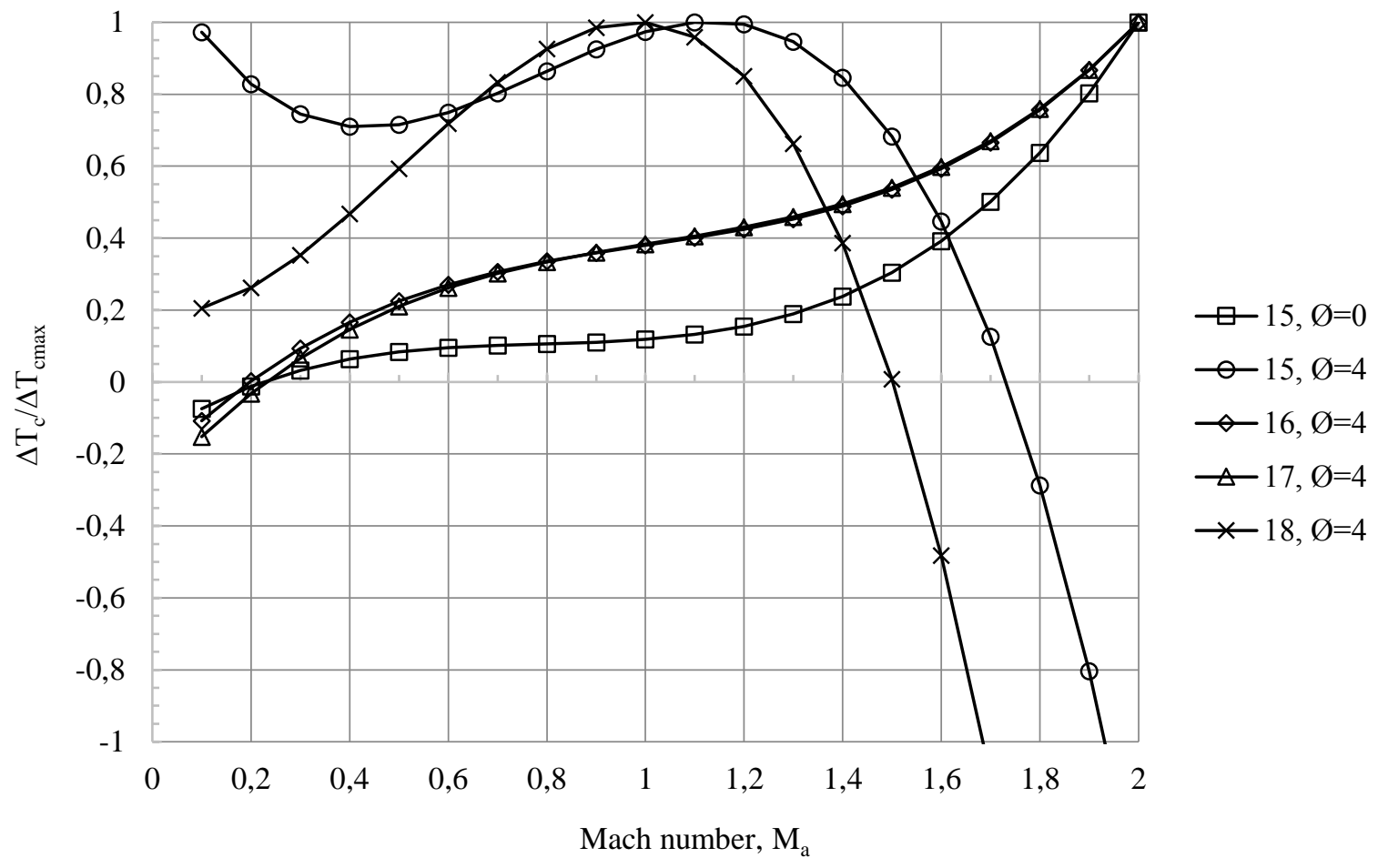

Figure 8. Effects of $\mathrm{L} / \mathrm{D}$ and $\mathrm{M}_{\mathrm{a}}$ on temperature separation

\section{Effect of Nozzle Number and Nozzle Geometry (Nn)}

Nozzle is the entry point through which air enters tangentially in the vortex tube. Extensive experimental and numerical work is evident for number of nozzles and nozzle geometry. Experimental work has been performed by $[15,16,7,17,18,19,20,21,22,23]$ with regard to nozzle number [24, 25] and nozzle geometry. Researchers have obtained varying results for effect of nozzle numbers on energy separation. Some of these have obtained better results at lower nozzle numbers while, few have obtained enhanced performance at higher nozzle numbers. It was also observed that spiral and helical nozzles have shown good performance compared to straight nozzles. Although for number of nozzles and nozzle geometry to use, there is no common agreement.

In view of this 2,4 and 6 nozzles were used with straight and spiral geometry. The effect of straight and spiral geometry on COP and $\Delta \mathrm{T}_{\mathrm{c}} / \Delta \mathrm{T}_{\mathrm{cmax}}$ is observed with change in CMF. Figure 9 and 10 shows that smaller nozzle number produce good temperature separation as compared to higher nozzle numbers, i.e. the performance of 2 nozzles is better than multiple nozzles, the result is in agreement with observation by these [7, 20, 19, 24] researchers. The reason of decay with increase in nozzle number is may be due to increased turbulence of the flow. It is also seen that the nozzle performance is CMF dependent, this agrees to the results of Chang et al. Chang [22] has observed that the nozzle number effect on energy separation is dependent on CMF.

Pourmahmoud [26] has also commented that the stagnation point moves to the farthest end of hot tube, when helical nozzles are used. The obtained results suggest that the Spiral nozzles perform well as compared to straight nozzles except for 6 nozzles with spiral entry. For 6 entry spiral nozzles, the average rise in COP is observed to be $20 \%$ more than the 2 nozzles with straight entry. This is in support of the results of Pourmahmoud et al. [26]. The Figure 9 and 10 indicate that the performance of nozzles for COP and $\Delta \mathrm{T}_{\mathrm{c}}$ is influenced by CMF except small deviations as seen in case of spiral nozzles with 2 and 4 entries. This influence is may be because of the backpressure and back flow that may occur in spiral nozzles. 


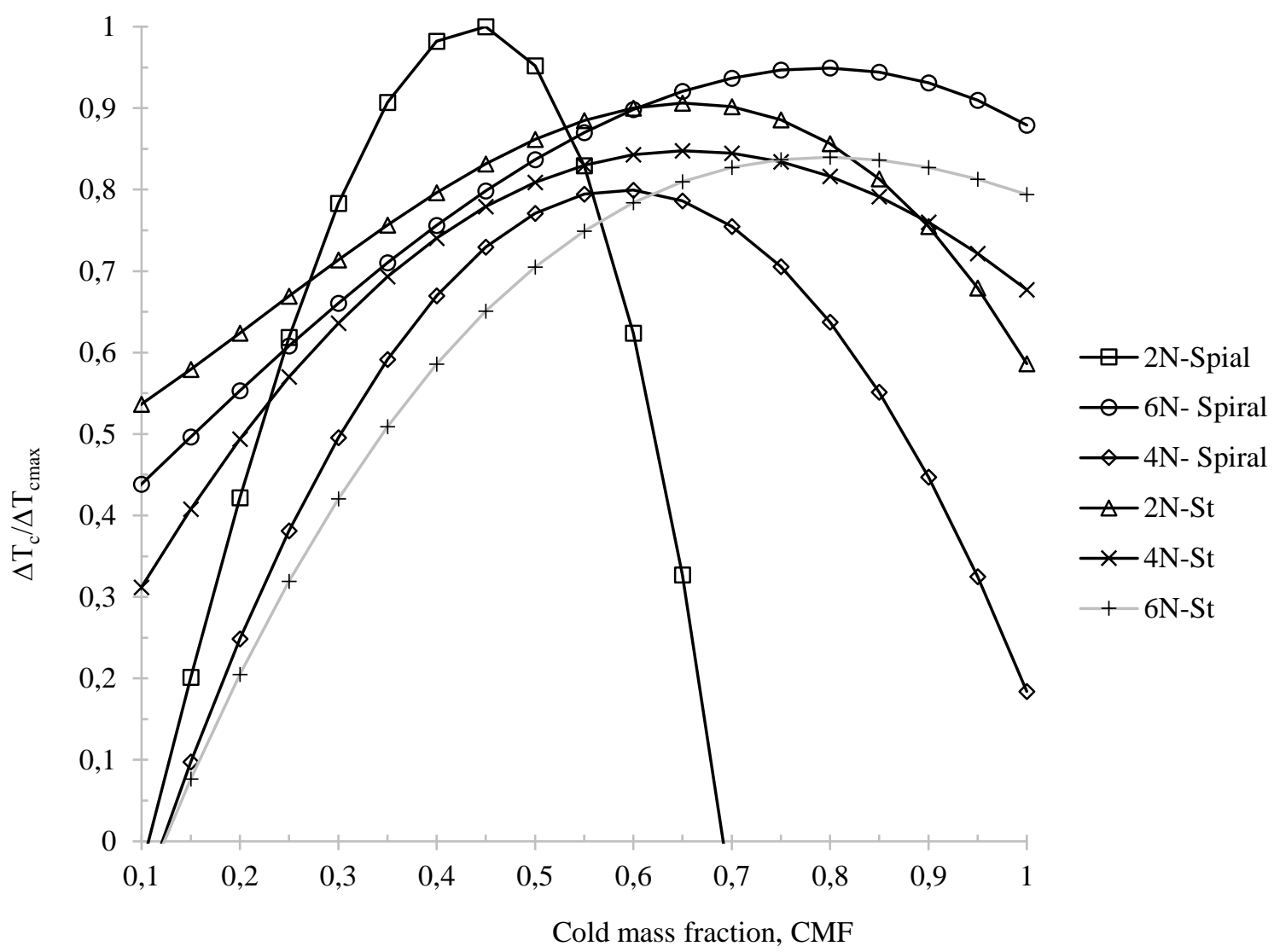

Figure 9. Effects of number of nozzles on temperature separation

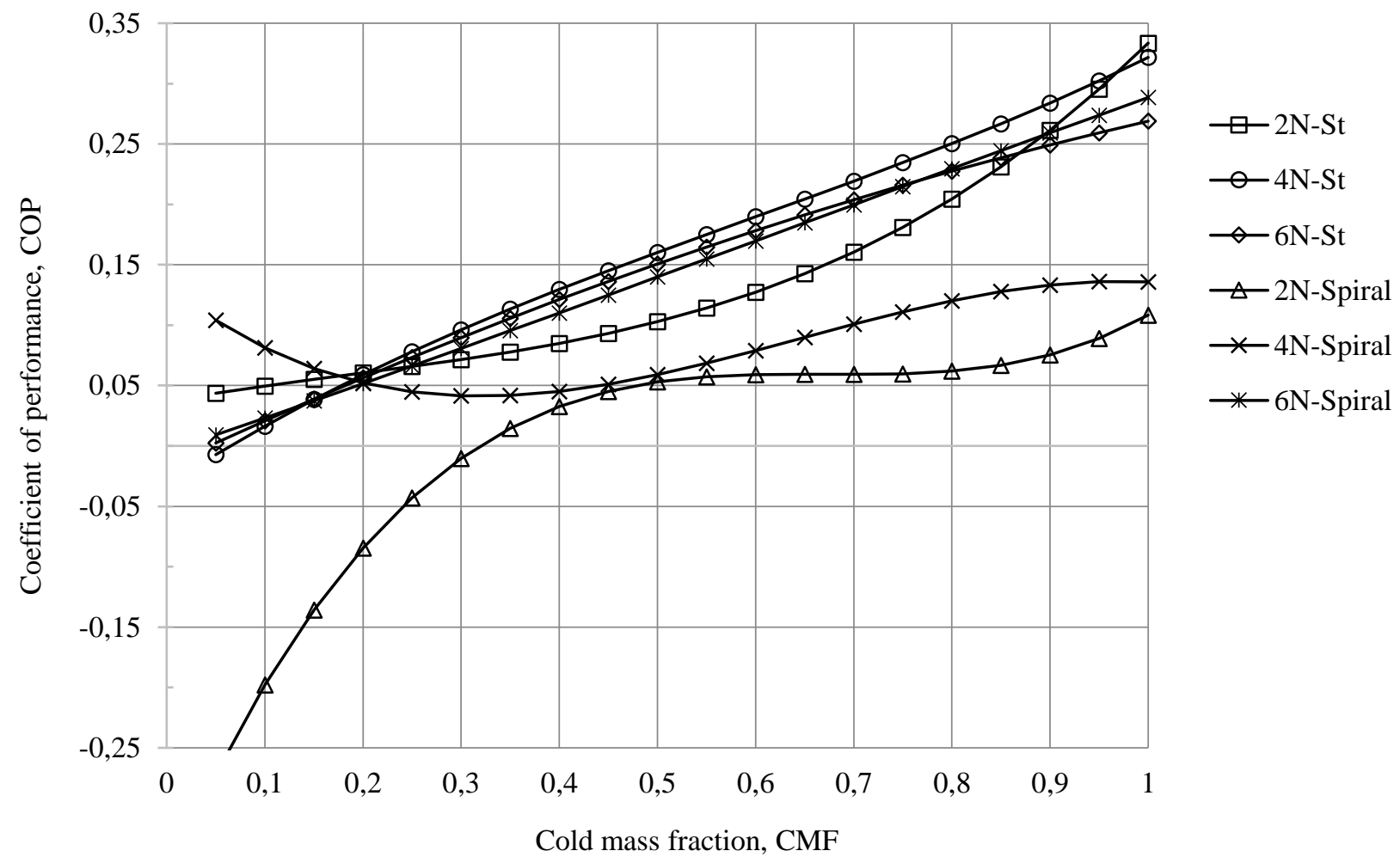

Figure 10. Effects of number of nozzles on COP 
The average COP of straight nozzles is $47 \%$ higher than spiral nozzles. Straight nozzles are better to obtain higher COP. Spiral nozzles produce better energy separation. Temperature separation in spiral nozzles increases with increase in nozzle number. The percentage increase in energy separation of 6 spiral nozzles is $98.31 \%$ higher compared to 2 and 4 spiral nozzles. While, percentage rise in energy separation as compared to straight nozzle is just $1.5 \%$ higher. This indicates that performance of straight nozzles is at par. The correlations for optimum performance of straight entry nozzles and spiral entry are developed as in Eguation 17. The coefficients of correlation for experimental range are as given in Table 2.

It has been observed that with increase in nozzle number, the optimum CMF shifts to higher values. I.e. in spiral nozzles, the percentage rise in CMF is $25 \%$ with increase in nozzle number. The rise in CMF is attributed to multiple entries increasing the swirl intensity. On the other hand, for straight nozzles it is 7 and $12.5 \%$ with increase in nozzle number from 2 to 6 .

\section{Effect of Cold Orifice Diameter ( $\left.d_{0}\right)$}

Cold orifice diameter through which cold stream leaves has been the topic of interest since the invention. Cold orifice diameter refers to cold diaphragm diameter or cold end diameter. These experimental $[2,27,15,5$, $28,7,17,6,29,30]$ studies have discussed the effect of cold end diameter $[22,31,23,25]$ on energy separation. Some studies [32] have reported that secondary circulation occurs because of cold orifice dimensions. Intensity of secondary circulations was observed to be more at diameter ratio $\left(d_{o} / D<0.5\right)$. Gulyaev [5] proposed that when $d_{o} / D$ equal to 0.565 the tube has shown maximum refrigeration capacity hence, $d_{o} / D$ should be in range of 0.5 to 0.57.Borisenko et al. [28] results have demonstrated that maximum temperature drop occurs at $d_{o} / D$ equal to 0.45 , whiletube operates with maximum efficiency at $d_{o} / D$ equal to 0.58 . It was also noted that with increase in orifice diameter efficiency increases along with CMF. Based on these observations in this study $d_{o} / D$ was selected as $0.4,0.48$ and 0.56 (5, 6 and $7 \mathrm{~mm}$ orifice diameter). The effect of these diameter ratios on $\mathrm{COP}$ and $\Delta \mathrm{T}_{\mathrm{c}} / \Delta \mathrm{T}_{\mathrm{cmax}}$ is shown in Figure 11 and 12. It can be seen that $d_{o} / D$ equal to 0.48 and 0.56 produce good temperature separation as compared to $d_{o} / D$ equal to 0.4 . Similar effect is observed for COP, the COP with $d_{o} / D$ equal to 0.48 and 0.56 is higher than $d_{o} / D$ equal to 0.4 . The reasons are obvious that at lower diameters, there is intense secondary circulation and it may cause mixing of the cold and hot streams. At lower values of diameter ratio, high backpressure exists, and at higher values of diameter ratio, higher tangential velocities exist thus reducing the performance as compared to larger diameters [17, 32].

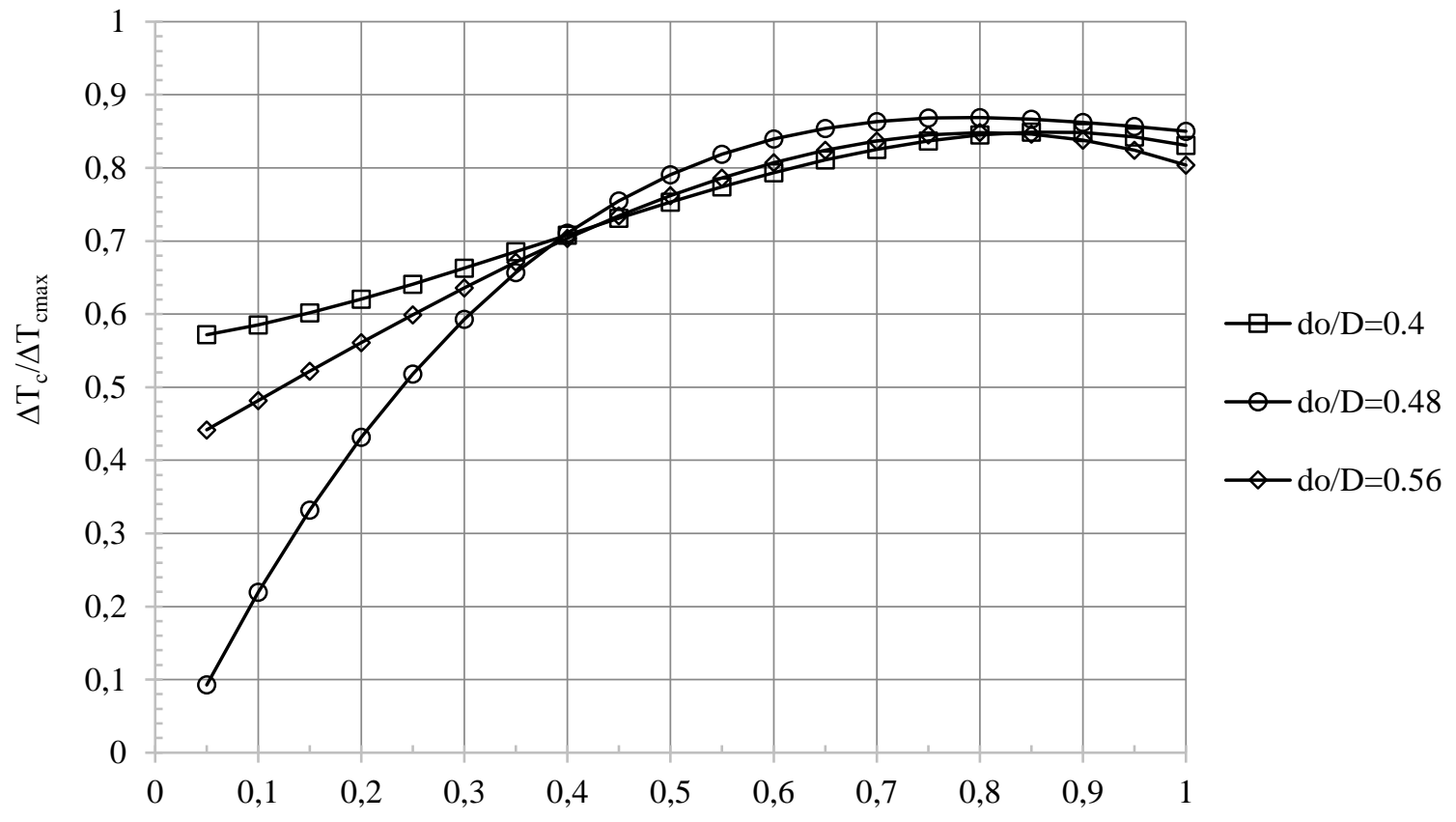

Cold mass fraction, $\mathrm{CMF}$

Figure 11. Effect of diameter ratio on energy separation 


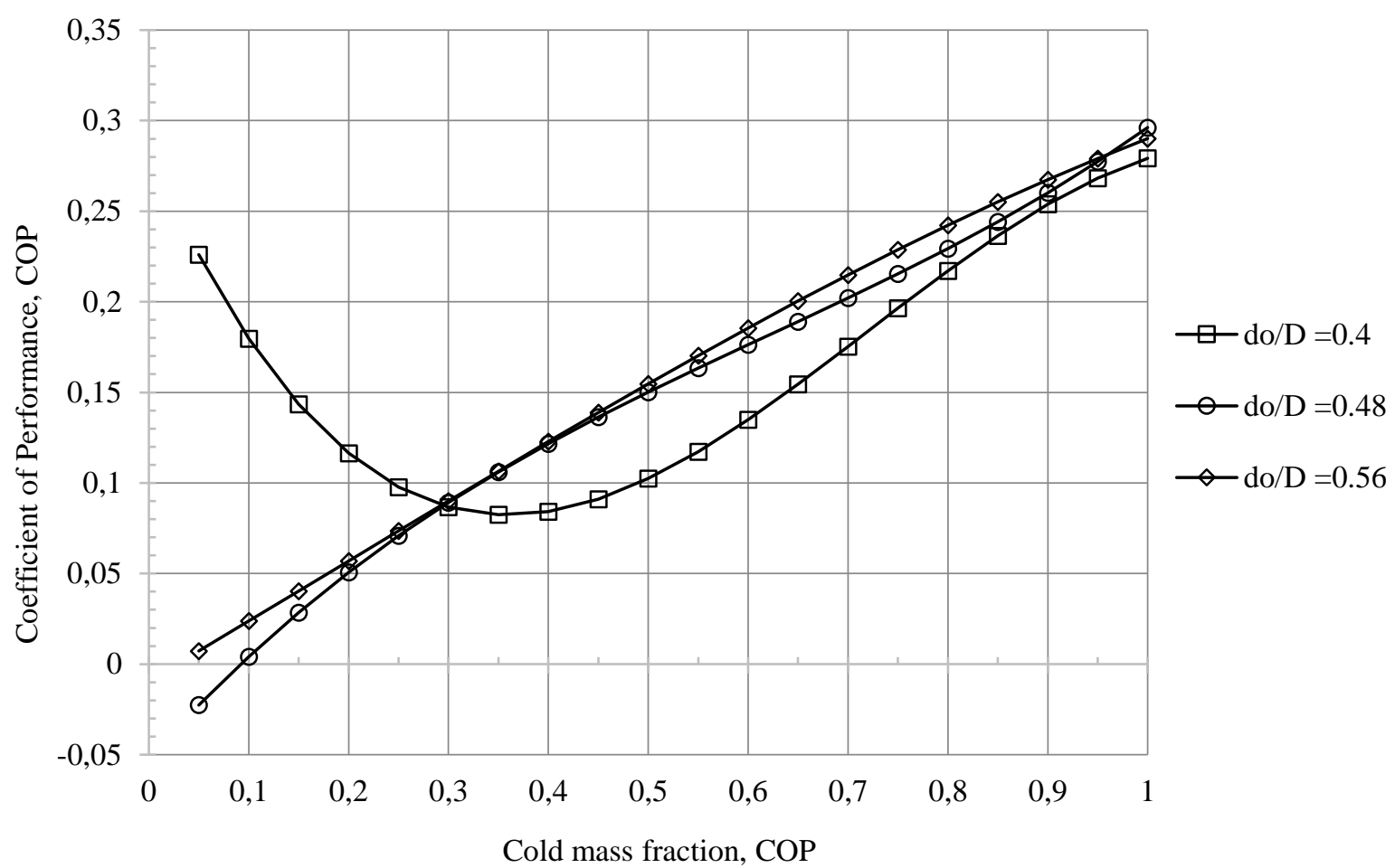

Figure 12. Effects of diameter ratio on COP

Figure 11 for temperature separation indicates higher values of separation for $d_{o} / D$ equal to 0.4 up to CMF equal to 0.4 and then it decreases. At CMF equal to 0.4 , the temperature separation is irrespective of diameter ratio. Similar results are observed for COP that at CMF equal to $0.3 \mathrm{COP}$ is irrespective of diameter ratio. Saidi and Valipour [7] experimentally observed that for $d_{o} / D<0.5$, cold end temperature difference increases, while at $d_{o} / D>0.5$, cold end temperature difference decreases. Temperature separation observed in the present study at $d_{o} / D$ equal to 0.4 is $7 \%$ higher than $d_{o} / D>0.5$. COP enhancement for $d_{o} / D>0.5$ is $5.1 \%$ than $d_{o} / D$ equal to 0.4 .

\section{Effect of Tube Angle ( $\phi)$}

Tube angle is one of the performance influencing parameters of vortex tube. Researchers have worked with straight, diverging, converging, curved and combination of tubes. The literature indicates that there were numerous studies performed on straight tube; very few studies have been reported with converging [33, 34] and diverging [5, 28, 35, 9, 36, 22, 37] tubes, tubes with curved geometry [31, 38, 39] and combination of straight and divergent/convergent sections [40, 41, 42].

Gulyaev [5] used divergent vortex tube in order to shorten the length of the tube. Gulyaev reported that tubes with 40 divergence angle should have L/D > 13 for obtaining better temperature drop. Chang et al. [22] reported maximum cooling efficiency for 40 divergence angle. In view of this for the present study divergence angle, $\varnothing$ is varied from $\varnothing$ equal to $0,2,3,4$ and 5 . As stated by Gulyaev L/D ratio was fixed to 15 for the study.

\section{Effect of CMF}

Figure 13 and 14 shows the effect of divergence angle on COP and $\Delta \mathrm{T}_{\mathrm{c}} / \Delta \mathrm{T}_{\mathrm{cmax}}$. It can be seen that the COP of diverging tube is on higher side as compared to straight tube. Highest COP of about 0.11 is obtained at $\varnothing$ equal to $2^{0}$. Overall, the COP of diverging tubes is $20 \%$ more than the straight tube; the reason is in divergent tubes the swirling velocity decreases, at reduced swirl velocity the friction losses and internal viscous losses are minimized, this may lead to increase in efficiency. 


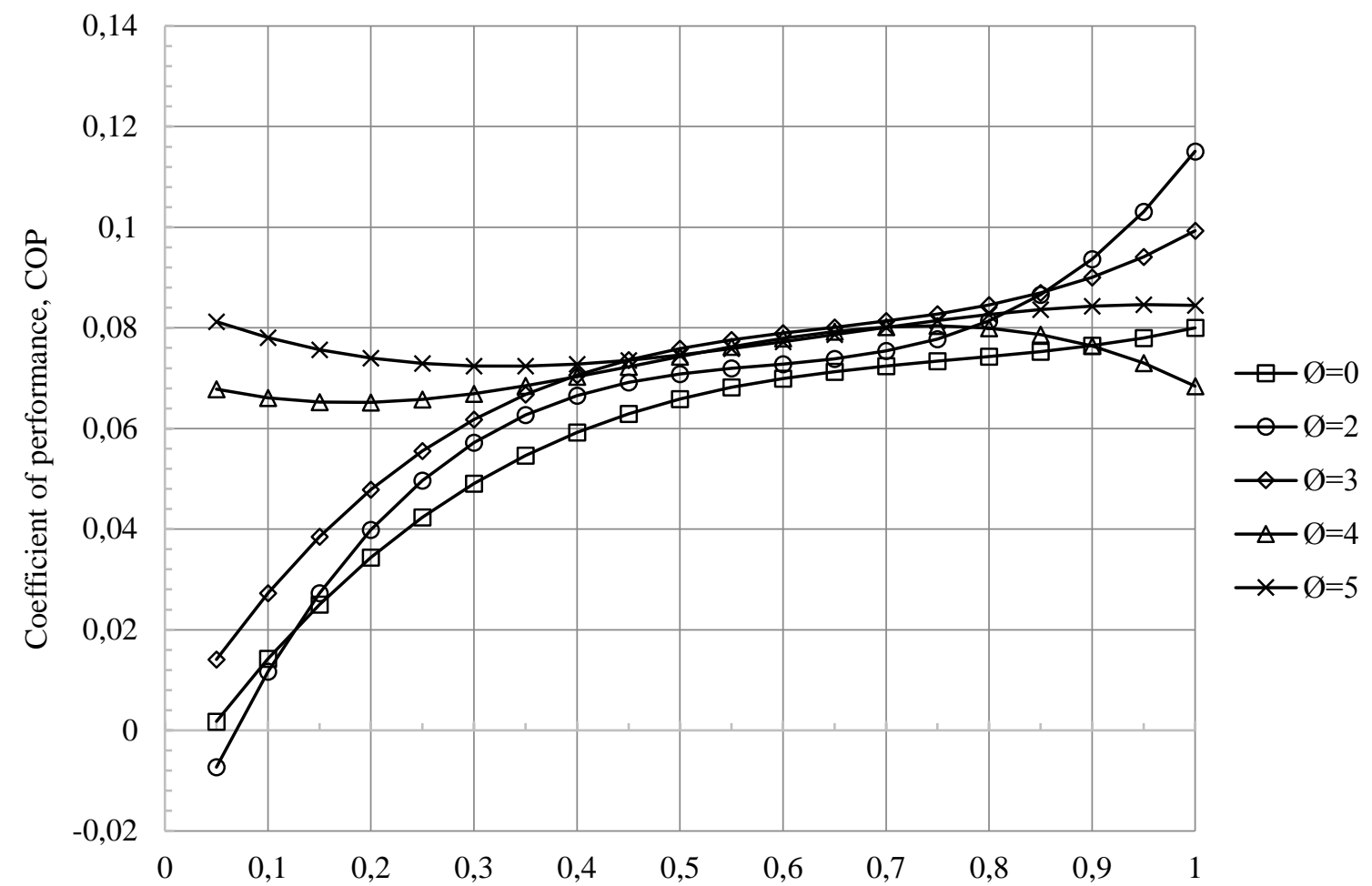

Cold mass fraction, $\mathrm{CMF}$

Figure 13. Effects of divergence angle, $\varnothing$ and CMF on COP

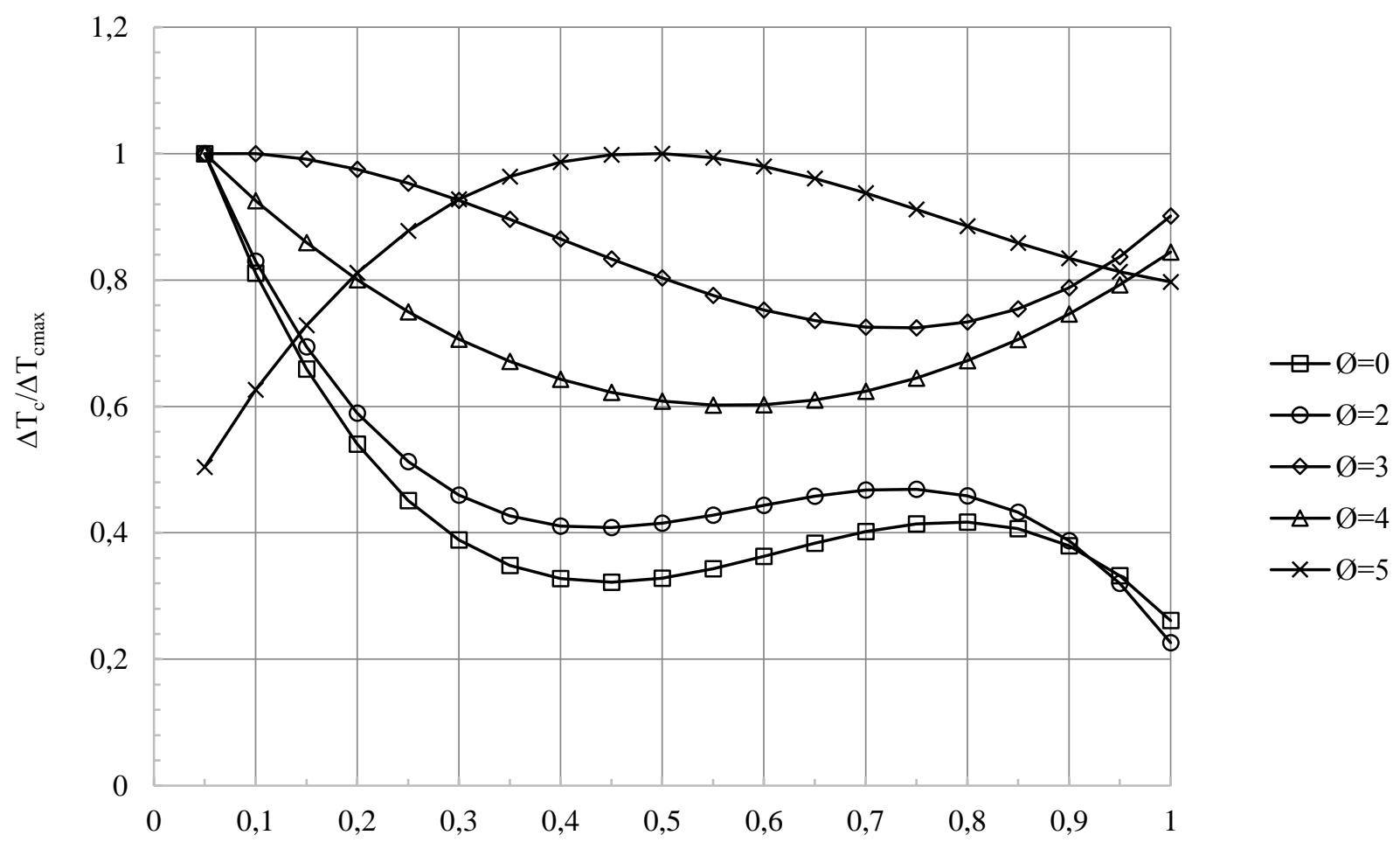

Cold mass fraction, $\mathrm{CMF}$

Figure 14. Effects of divergence angle, $\varnothing$ and CMF on temperature separation

Temperature separation on the other hand in case of diverging tubes is CMF dependent. The temperature separation varies with CMF for all divergence angles including straight tube. The highest temperature separation 
is shown by tube with $\varnothing$ equal to $5^{0}$ at CMF equal to 0.4 . For lower and higher CMF values other than 0.4 , the temperature separation decreases. This in agreement with the findings of Pouraria and Zangooee [43], they confirmed that performance of tube improves with divergence angle but cold mass fraction limits the optimum divergence angle for maximum efficiency. Temperature separation observed for $\varnothing$ equal to 3,4 and 5 , is higher than straight tube and $\varnothing$ equal to 2 . The temperature separation in diverging tubes is $38 \%$ more than straight tube. The reason behind performance enhancement in diverging tube is that diverging tube adopts volume changes of gas and mixing of cold and hot stream is minimized in diverging tubes. Observe similar findings and the results are in good agreement with the literature $[28,35,37]$.

\section{Effect of Mach Number}

Figure 15 and 16 shows effect of Ma on COP and $\Delta \mathrm{T}_{\mathrm{c}} / \Delta \mathrm{T}_{\mathrm{cmax}}$, Mach number at inlet has significant effect on COP with diverging tubes. Straight tube has shown rise in performance at supersonic Ma, this may be because of the effect of vortex deceleration as observed by Chang et al. [22].In addition, for subsonic Ma, the COP of all the diverging tubes does not show significant variations. Effect of Ma on temperature separation is shown in Figure 15 Tube with divergence angle, $\varnothing$ equal to 4 has provided high temperature separation at all Sonic, sub sonic and hypersonic Ma, The temperature separation for $\varnothing$ equal to 4 decreases beyond Ma equal to 1.4. Thus, Straight tubes provide higher $\mathrm{COP}$ at all $\mathrm{Ma}$ and diverging tubes provide good temperature separation. Temperature separation for $\varnothing$ equal to 4 is almost more than $100 \%$ as compared to all other tubes including straight tube.

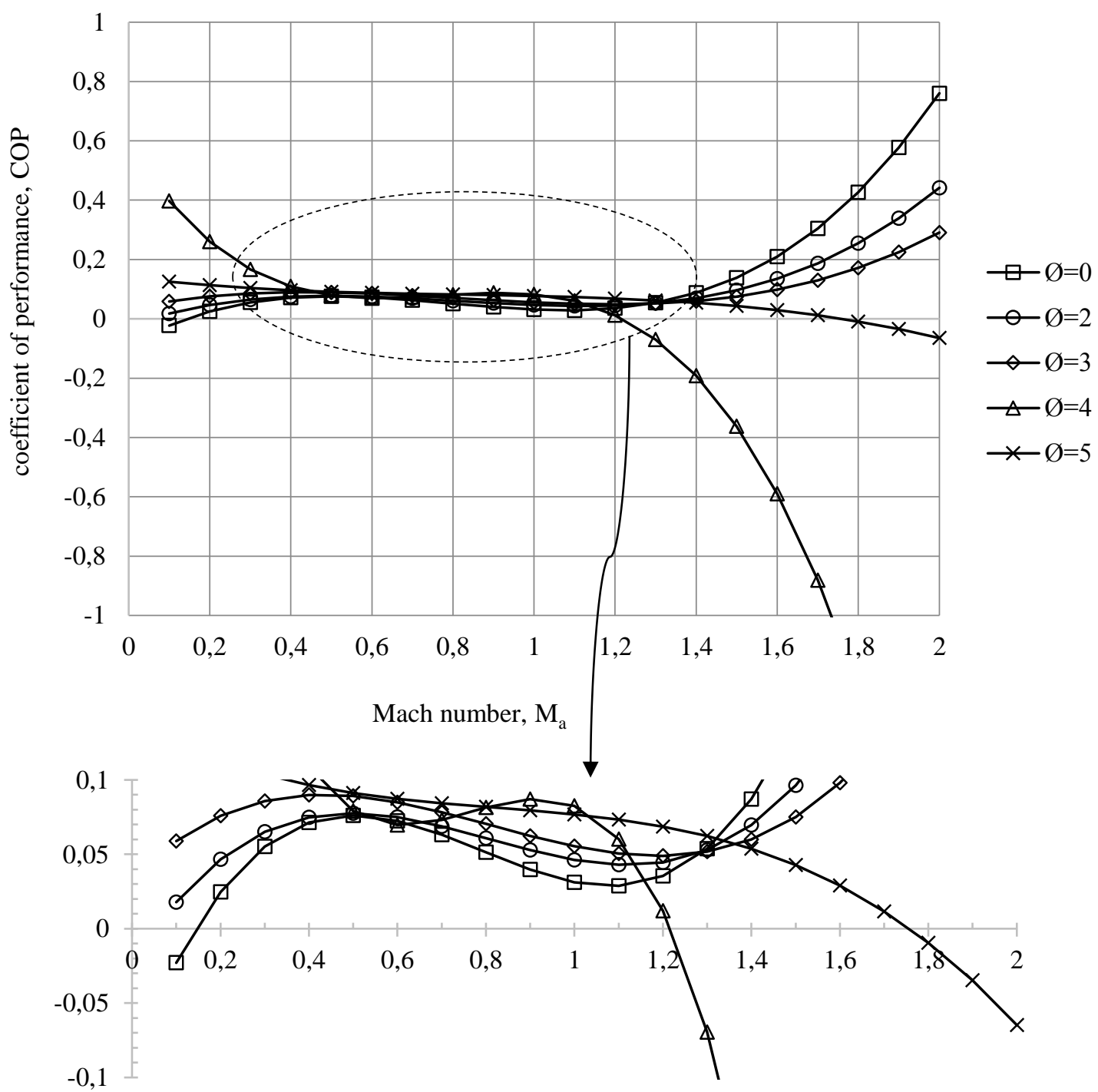

Figure 15. Effects of divergence angle, $\varnothing$ and Ma on COP 


\section{Comparison of COP}

Figure 17 shows COP comparisons of straight, diverging and converging tubes [41]. The comparison is made with the results of earlier work. It is seen that COP of diverging tubes is much higher that straight and converging tubes. The average increase in COP of diverging tubes as compared to straight tubes is $97 \%$ and as that of converging tubes, the rise is almost $140 \%$. Thus diverging tubes is a good geometry alternative to straight and converging tube. The correlations for optimum performance of divergence angle for the experimented range of parameters are as follows, the correlations are as given in Table 2.

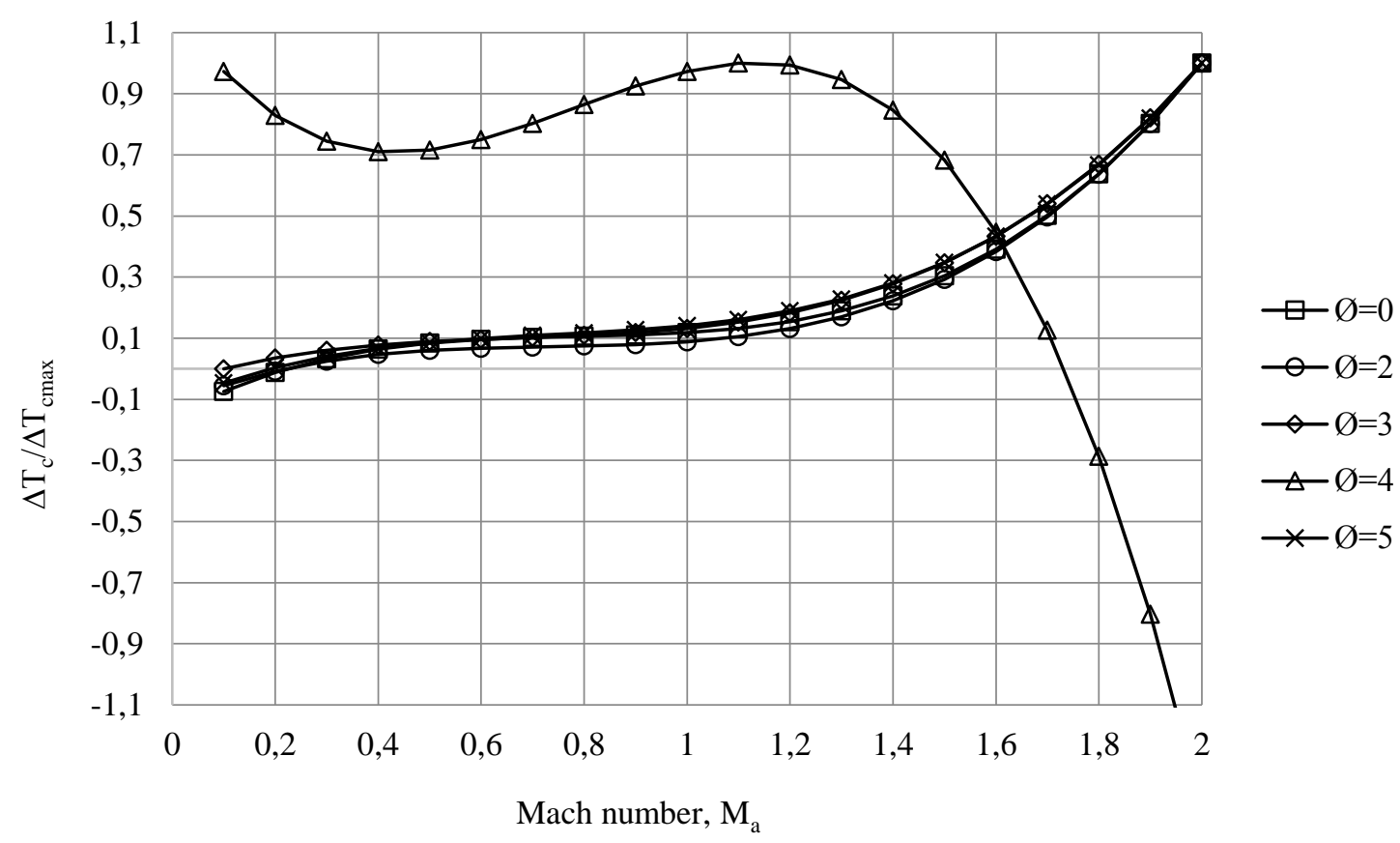

Figure 16. Effects of divergence angle, $\varnothing$ and Ma on temperature separation

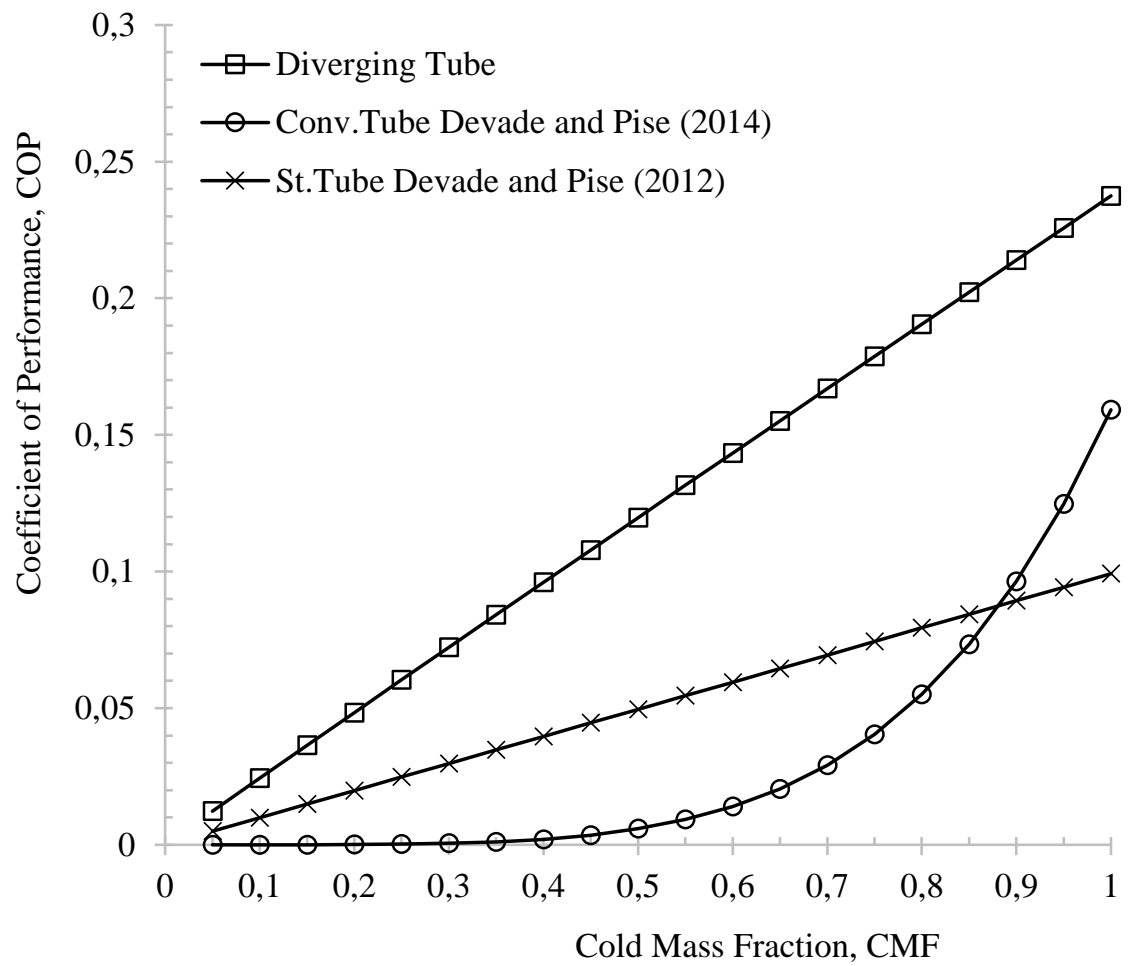

Figure 17. COP comparisons of straight, diverging and converging tubes 


\section{Effect of Hot Exit Valve Angles $(\theta)$}

Plugs used on hot end side restrict the peripheral flow. These plugs/valves/cone angle and geometry have considerable effect on energy separation. The positions of these valves/plugs determine the cold mass fraction and in turn the energy separation.

Many researchers during their experimental studies [44, 45, 6, 46, 11, 47, 40, 48, 24, 41] have used different valves [37, 25] and shapes. Dyskin [45] used detwister on hot end and observed that the heating effect increase by 3 to $5^{0}$. Detwister improves swirling intensity and hence both heating as well as cooling performance of tube enhances. Dincer et al. used conical valves [46] and reported that maximum temperature difference occurs at 30 and $60^{\circ}$ valve angle. Devade and Pise [40] utilized the effect of valve angles to enhance efficiency of the tube, and observed that $60^{\circ}$ angles valve was best for heating and $45^{\circ}$ angles valve improves overall performance (cooling as well as heating).

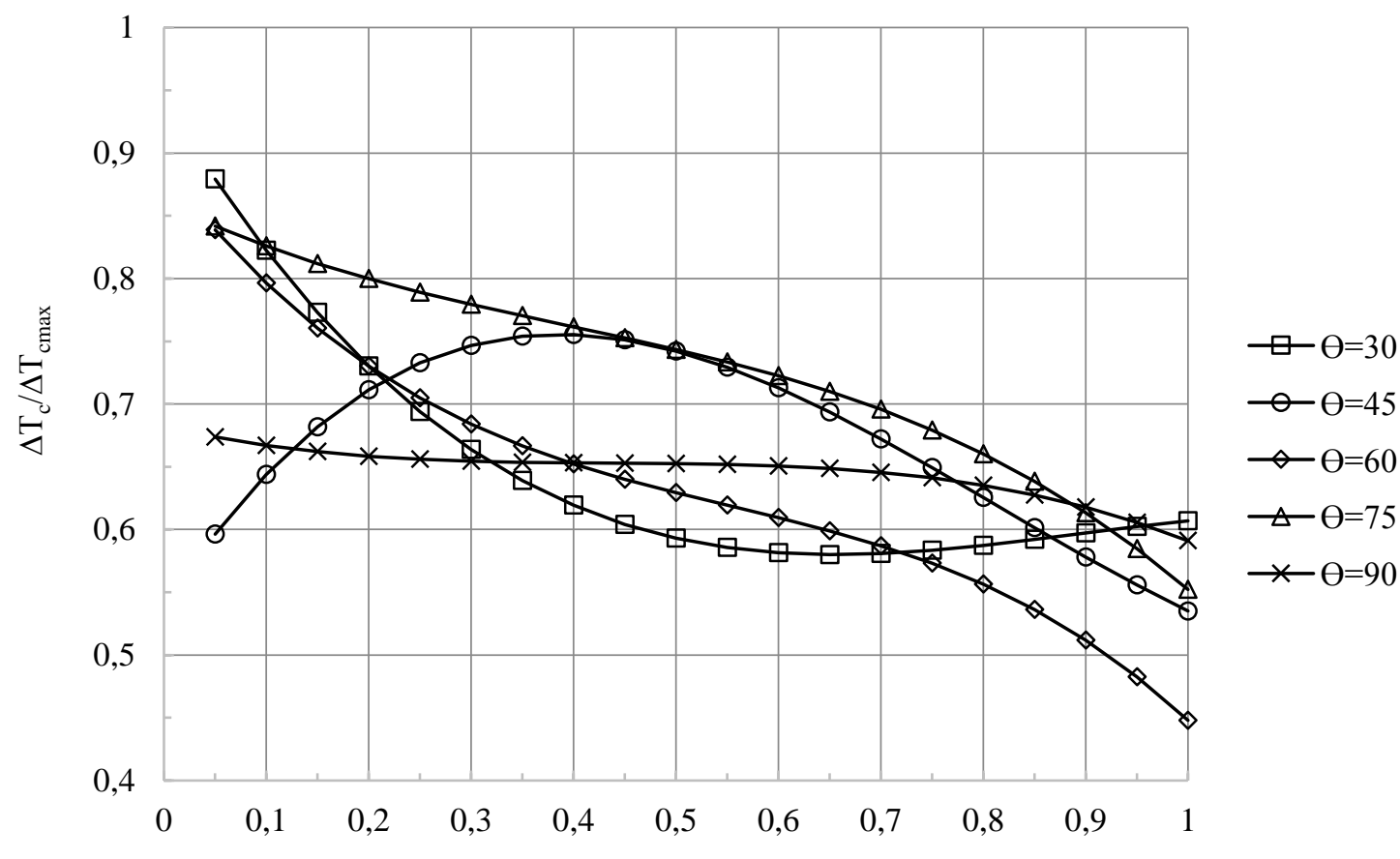

Cold mass fraction, $\mathrm{CMF}$

Figure 18. Effects of valve angle, $\Theta$ and $\mathrm{CMF}$ on temperature separation

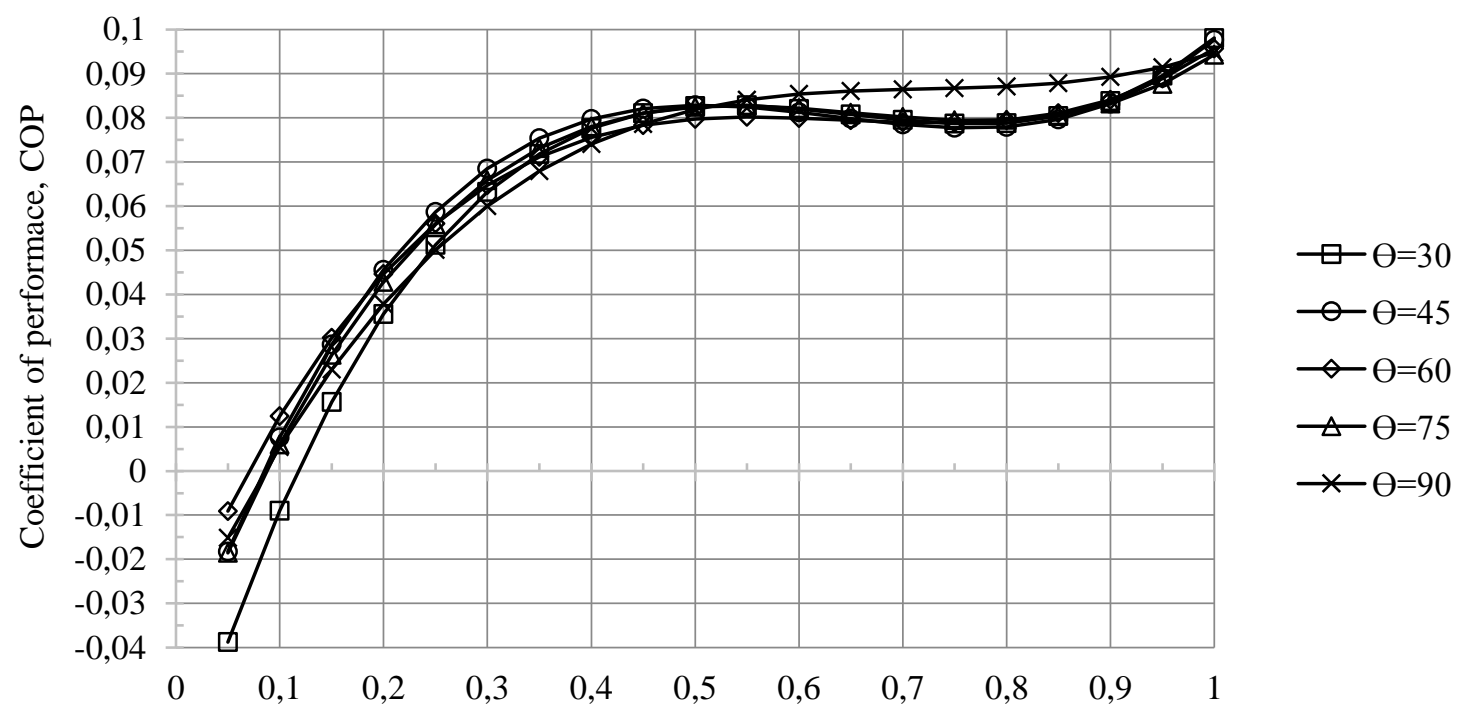

Cold mass fraction, $\mathrm{CMF}$

Figure 19. Effects of valve angle, $\Theta$ and $\mathrm{CMF}$ on $\mathrm{COP}$ 
For the present study, conical hot end valve angles in the range of $\Theta$ equal to 30 to $90^{\circ}$ are used with a step of $15^{\circ}$. Figure 18 and 19 shows the effect of conical valve angles on COP and $\Delta \mathrm{T}_{\mathrm{c}} / \Delta \mathrm{T}_{\text {cmax }}$. CMF significantly influences the effect of valve angles on $\Delta \mathrm{T}_{\mathrm{c}} / \Delta \mathrm{T}_{\mathrm{cmax}}$. The temperature separation decreases, with increase in CMF. $\Theta$ equal to $90^{\circ}$ has consistent but comparatively less temperature separation irrespective of CMF, this may be because at higher valve angles, there are sudden changes in flow directions. Markal et al. [11] reported that the instability in flow at higher valve angles reduce the performance of the tube. COP as shown in Figure 18 increases with CMF at all valve angles. Thus, valve angles have significant effect on temperature separation than COP. At certain CMF values, the temperature separation is irrespective of valve angles. The temperature profiles cross each other at certain CMF values as seen in Figure17. Rafiee et.al [49] has demonstrated that the valve angles have influence on temperature separation because of the displacement of stagnation point in the flow-field. They observed the shift of stagnation point towards cold end with increase in valve angle. The shift of stagnation point is also dependent on CMF. Stagnation point and CMF govern the temperature separation in vortex tube.

The correlations for optimum performance of hot end valve angle for the experimented range of parameters are as follows, the correlations are as given in Table 2.

\section{Effect of Cold Mass Fraction (CMF)}

Cold mass fraction is the ratio of cold mass of air to the total mass of air supplied. CMF exerts limitation to the performance enhancement with almost all of the geometry parameters. Thus, CMF happens to be the significant parameter governing the tube performance.

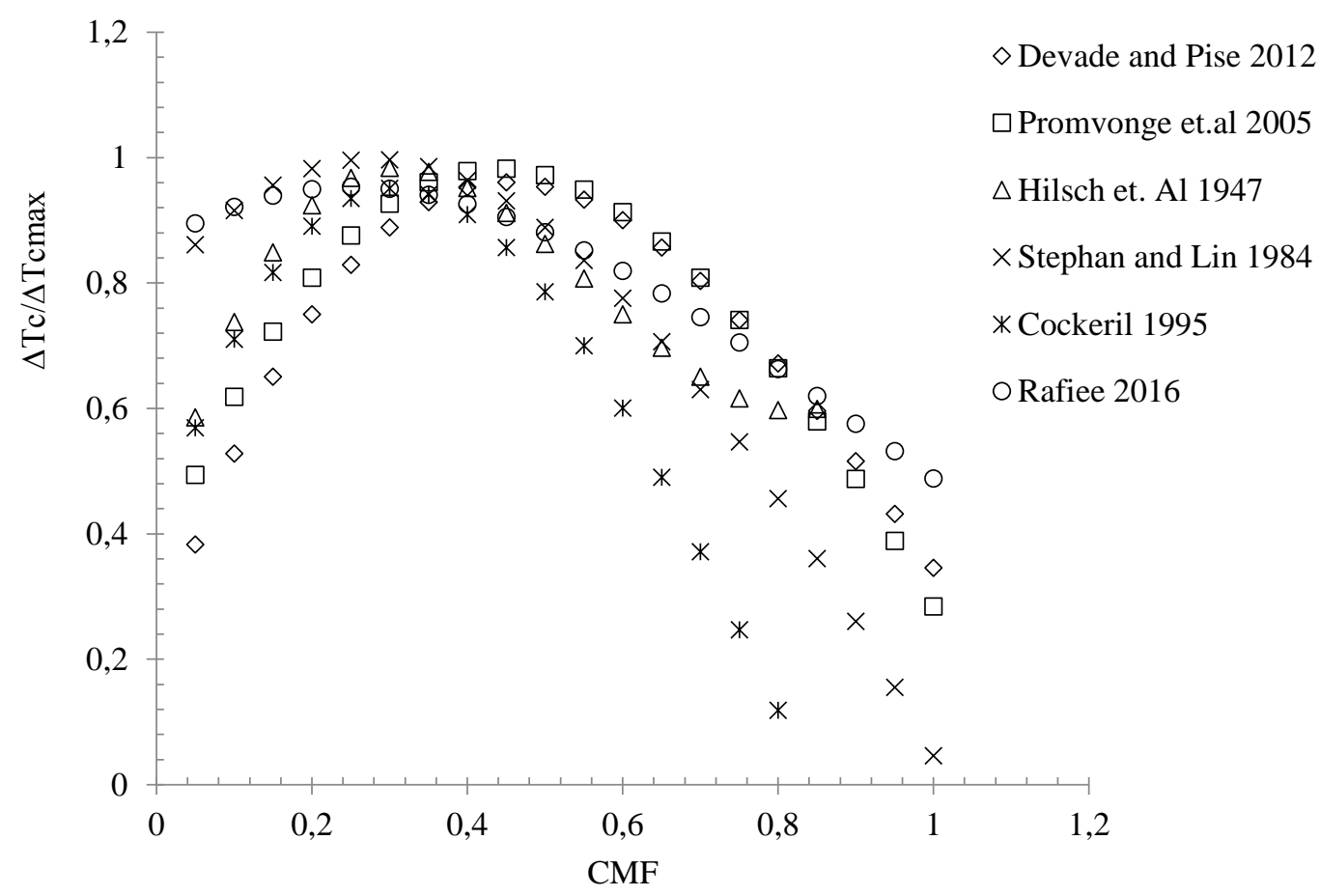

Figure 20. Effect of CMF on temperature separation

Saidi and Yazdi [10]studied the effects of CMF on energy separation and exergy destruction. They found that the device performs better at CMF equal to 0.7 because exergy destruction is minimum. Promvonge and Eiamsa-ard [17] experimentally noticed that the highest cold end temperature drop is obtained at CMF equal to 0.345 for tubes with and without insulation. However, it is an observation that at highest cold end temperature drop the tube efficiency significantly reduces, the reason behind drop in efficiency is the lower CMF obtained.

A correlation proposed by Hilsch [2] for temperature drop in terms of CMF is as follows,

$$
\begin{gathered}
\frac{\Delta t_{c}}{\Delta t_{c, \text { max }}}=1.0916(C M F)^{3}-4.2581(C M F)^{2}+2.8563 C M F+0.4641 \\
\frac{\Delta t_{c}}{\Delta t_{c, \max }}=5.78(C M F)^{3}-9.8(C M F)^{2}+4.4 C M F+0.39
\end{gathered}
$$


Devade and Pise [37] also proposed relation for Temperature drop as,

$$
\frac{\Delta t_{c}}{\Delta t_{c, \max }}=1.0916(C M F)^{3}-4.2581(C M F)^{2}+2.8563 C M F+0.464
$$

The correlation proposed by Stephan and Lin [50] was,

$$
\frac{\Delta t_{c}}{\Delta t_{c, \max }}=0.815(C M F)^{3}-3.101(C M F)^{2}+1.54 C M F+0.792
$$

Cockerill also have proposed such relationship between CMF and temperature ratio,

$$
\frac{\Delta t_{c}}{\Delta t_{c, \max }}=3.23(C M F)^{3}-7.97(C M F)^{2}+3.97 C M F+0.39
$$

The correlation dictates the effect of CMF on temperature drop.Figure 20 shows the effect of CMF on temperature separation. It indicates that maximum temperature drop occurs at optimum CMF [37]. There is good agreement of the results of all the correlations.

With the present study the CMF has put limitation to $\mathrm{L} / \mathrm{D}$ ratio, it has been discussed that $\mathrm{COP}$ and $\Delta \mathrm{T}_{\mathrm{c}}$ $/ \Delta \mathrm{T}_{\text {cmax }}$ increases up to $\mathrm{L} / \mathrm{D}$ equal to 17 and then it decreases. Influence of CMF on performance of spiral nozzles is more than straight nozzles. Significant effect of CMF is observed for smaller orifice diameters with. For diameters with $d_{o} / D \geq 0.5$, the effect of CMF is less significant. Diverging tube provides better COP, but temperature separation in diverging tubes is CMF dependant. Similar to $\varnothing$, hot end valve angle $(\Theta)$ performance for temperature separation largely depends on CMF. Thus, more or less, CMF has major effect on performance of vortex tube.

The conclusion from the discussion in this is that, cold mass fraction significantly affects the operation of vortex tube. It limits the energy separation. Cold mass fraction puts limit on the L/D ratio, cold orifice diameter, divergence angle, number of nozzles, valves on hot end side.

\section{CONCLUDING REMARKS}

The results for effect of CMF and Ma on L/D ratio, divergence angle Ø and other geometry parameters like $N_{n}$, nozzle geometry, cold orifice dia. do and hot end valve angle $\Theta$, on COP and $\Delta T_{c}$, the following inferences are drawn,

i. Cold mass fraction limits the use of L/D ratio. Up to certain L/D the performance increases and then it drops. $\mathrm{L} / \mathrm{D} 17$ contributes to attain higher COP and $\Delta \mathrm{T}_{\mathrm{c}}$ at $\mathrm{CMF}$ equal to 0.78 . COP for all $\mathrm{L} / \mathrm{D}$ ratio increases with CMF but temperature separation is $\mathrm{CMF}$ dependent.

ii. The percentage rise in COP with increase in $\mathrm{L} / \mathrm{D}$ is $31 \%$ up to $\mathrm{L} / \mathrm{D}$ equal to 17 . At $\mathrm{L} / \mathrm{D} 18$, it drops by $20 \%$.

iii. Mach number at inlet affects $\mathrm{COP}$ of the vortex tube, but yields better temperature separation for straight tube. Straight tubes can provide good temperature separation and COP together, when operated at supersonic Ma.

iv. The percentage increase in energy separation of 6 spiral nozzles is $98.31 \%$ higher compared to 2 and 4 spiral nozzles. While, percentage rise in energy separation as compared to straight nozzle is just $1.5 \%$ higher. This indicates that performance of straight nozzles is at par.

v. For the present study, 2 nozzles have outperformed than multiple entries, The COP for spiral entry 6 nozzle is observed to be $20 \%$ higher as compared to straight entry 2 nozzles. Performance of all nozzles varies, with change in CMF.

vi. It has been observed that with increase in nozzle number, the optimum CMF shifts to higher values i.e. in spiral nozzles, the percentage rise in CMF is $25 \%$ with increase in Nozzle number. On the other hand, for straight nozzles it is 7 and $12.5 \%$ with increase in nozzle number. 
vii. Energy separation and COP is more for larger orifice diameters $\left(d_{o} / D>0.5\right)$. CMF has substantial effect on energy separation and COP for $d_{o} / D<0.5$.

viii. Temperature separation observed in the present study at $d_{o} / D$ equal to 0.4 is $7 \%$ higher than $d_{o} / D>$ 0.5 . COP enhancement for $d_{o} / D>0.5$ is $5.1 \%$ than $d_{o} / D$ equal to 0.4 .

ix. COP for diverging tubes is $20 \%$ higher than straight tubes. Temperature separation is dependent on CMF for diverging and straight tubes.

x. Straight tubes provide higher COP at sonic, subsonic and supersonic Ma. While, diverging tube with Ø equal to 4 has shown good temperature separation up to Ma equal to 1.4, the performance declines above Ma equal to 1.4 to 2 .

xi. Temperature separation for hot end valves is dependent upon CMF, and at all valve angles COP increases with CMF.

xii. $\quad$ CMF is found to be significant performance deciding parameter as far as temperature separation is concerned. COP exerts limitation on every geometry parameter significantly. CMF and stagnation point govern the performance of vortex tube.

xiii. Correlations have been proposed for optimum performance of $\mathrm{L} / \mathrm{D}$ ratio in terms of COP, CMF and $\Delta \mathrm{T}_{\mathrm{c}}$ $/ \Delta \mathrm{T}_{\text {cmax. }}$

xiv. The similarity relation developed is also in good agreement with the literature.

CMF being significant parameter, future scope lies in deciding the geometry combination based on CMF to get the optimized results. The temperature separation limits put by CMF need extension in future.

\section{NOMECLATURE}

\section{A Area, $\mathrm{mm}^{2}$}

$\mathrm{C}_{\mathrm{p}} \quad$ Specific heat, $\mathrm{KJ}^{-} \mathrm{kg}^{-1} \mathrm{k}^{-1}$

D Diameter of the tube, $\mathrm{mm}$

$\mathrm{L} \quad$ length of tube, $\mathrm{mm}$

m mass flow rate, $\mathrm{kg}-\mathrm{sec}^{-1}$

M Mach number

N Number

Q Heat added, dissipated, refrigeration effect,KJ- $\mathrm{kg}^{-1}$

$\mathrm{R} \quad$ Gas constant, $\mathrm{KJ}-\mathrm{kg}^{-1} \mathrm{k}^{-1}$, Coefficient of regression

d diameter,mm

$\mathrm{t}$ temperature, $\mathrm{K}$

p I $\quad$ It $^{\text {st }}$ term coefficient

q $\quad I^{\text {nd }}$ term coefficient

r $\quad$ III ${ }^{\text {rd }}$ term coefficient

$\mathrm{s} \quad \mathrm{IV}^{\text {th }}$ term coefficient

z Non dimensional geometry parameter

$\Delta \quad$ Difference, $\mathrm{K}$

$\gamma \quad$ index of expansion

$\eta \quad$ efficiency

$\Theta \quad$ hot end valve angle, $\left({ }^{0}\right)$

$\varnothing \quad$ tube divergence angle, $\left({ }^{0}\right)$

CMF cold mass fraction

L/D length to diameter ratio

$\mathrm{M}_{\mathrm{a}} \quad$ Mach number

$\frac{\Delta T_{C}}{\Delta T_{\text {cmax }}}$ Cold end temperature ratio

$\frac{\emptyset}{\emptyset_{\max }}$ Divergence angle ratio

$\frac{\theta}{\theta_{\max }} \quad$ Valve angle ratio

a ambient 


$\begin{array}{ll}\mathrm{c} & \text { cold } \\ \mathrm{h} & \text { hot } \\ \mathrm{i} & \text { inlet } \\ \text { is } & \text { isentropic } \\ \max & \text { maximum } \\ \mathrm{n} & \text { nozzle } \\ \mathrm{o} & \text { orifice } \\ \text { opt } & \text { optimum } \\ \mathrm{t} & \text { tube }\end{array}$

\section{REFERENCES}

[1] Ranque, G. J. (1933). Expériencesd sur la detente giratoire avec productions simultanes d'un echappment d'air chand et d'un echappment d'air froid. Journal de Physique et Le Radium, 112-114.

[2] Hilsch, R. (1947). The use of the expansion of gases in a centrifugal field as cooling process. Review of Scientific Instruments, 18(2), 108-113.

[3] Westley, R. (1954). A bibliography and survey of the vortex tube.

[4] Brun, M. E. (1933). A propose de la communication by Ranque. J de Phys et le radium.

[5] Gulyaev, A. I. (1966). Investigation of conical vortex tubes. Journal of Engineering Physics and Thermophysics, 10(3), 193-195.

[6] Aydin, O., Baki, M. (2006). An experimental study on the design parameters of a counterflow vortex tube. Energy, 31(14), 2763-2772.

[7] Saidi, M. H., Valipour, M. S. (2003). Experimental modeling of vortex tube refrigerator. Applied Thermal Engineering, 23(15), 1971-1980.

[8] Cockerill T.T. (1995). Thermodynamic and Fluid Mechanics of Ranque -Hilsch vortexs Tube. Master Thesis, University of Cambridge, England.

[9] Piralishvili, S. A., Polyaev, V. M. (1996). Flow and thermodynamic characteristics of energy separation in a double-circuit vortex tube - an experimental investigation. Experimental Thermal and Fluid Science, 12(4), 399410 .

[10] Saidi, M. H., Yazdi, M. A. (1999). Exergy model of a vortex tube system with experimental results. Energy, 24(7), 625-632.

[11] Markal, B., Aydın, O., Avcı, M. (2010). An experimental study on the effect of the valve angle of counterflow Ranque-Hilsch vortex tubes on thermal energy separation. Experimental Thermal and Fluid Science, 34(7), 966-971.

[12] Behera, U., Paul, P. J., Dinesh, K., Jacob, S. (2008). Numerical investigations on flow behaviour and energy separation in Ranque-Hilsch vortex tube. International Journal of Heat and Mass Transfer, 51(25-26), 6077-6089. [13] Aljuwayhel, N. F., Nellis, G. F., Klein, S. A. (2005). Parametric and internal study of the vortex tube using a CFD model. International Journal of Refrigeration, 28(3), 442-450.

[14] Bramo, A. R. (2010). N. pourmahmoud, CFD simulation of length to diameter ratio effects on the energy separation in a vortex tube. Journal of Thermal sciences, 1-16.

[15] Takahama, H. (1965). Studies on vortex tubes:(1) experiments on efficiency of energy separation:(2) on profiles of velocity and temperature. Bulletin of JSME, 8(31), 433-440.

[16] Takahama, H., Soga, N. (1966). Effects of cold air rate and partial admission of nozzle on the energy separation. Japan Society of Mechanical Engineers, 9(33), 121-130.

[17] Promvonge, P., Eiamsa-ard, S. (2005). Investigation on the vortex thermal separation in a vortex tube refrigerator. Science Asia, 31(3), 215-223.

[18] Dincer, K., Tasdemir, S., Baskaya, S., Uysal, B. Z. (2008). Modeling of the effects of length to diameter ratio and nozzle number on the performance of counterflow Ranque-Hilsch vortex tubes using artificial neural networks. Applied Thermal Engineering, 28(17-18), 2380-2390.

[19] Kirmaci, V. (2009). Exergy analysis and performance of a counter flow Ranque-Hilsch vortex tube having various nozzle numbers at different inlet pressures of oxygen and air. International Journal of Refrigeration, 32(7), 1626-1633. 
[20] Dincer, K., Avci, A., Baskaya, S., Berber, A. (2010). Experimental investigation and exergy analysis of the performance of a counter flow Ranque-Hilsch vortex tube with regard to nozzle cross-section areas. International Journal of Refrigeration, 33(5), 954-962.

[21] Eiamsa-Ard, S. (2010). Experimental investigation of energy separation in a counter-flow Ranque-Hilsch vortex tube with multiple inlet snail entries. International Communications in Heat and Mass Transfer, 37(6), 637643.

[22] Chang, K., Li, Q., Zhou, G., Li, Q. (2011). Experimental investigation of vortex tube refrigerator with a divergent hot tube. International Journal of Refrigeration, 34(1), 322-327.

[23] Mohammadi, S., Farhadi, F. (2013). Experimental analysis of a Ranque-Hilsch vortex tube for optimizing nozzle numbers and diameter. Applied Thermal Engineering, 61(2), 500-506.

[24] Avc1, M. (2013). The effects of nozzle aspect ratio and nozzle number on the performance of the RanqueHilsch vortex tube. Applied Thermal Engineering, 50(1), 302-308.

[25] Bovand, M., Rashidi, S., Esfahani, J. A. (2016). New design of Ranque-Hilsch vortex tube: helical multiintake vortex generator. Journal of Thermophysics and Heat Transfer, 608-613.

[26] Pourmahmoud, N., Hassanzadeh, A., Moutaby, O. (2012). Numerical analysis of the effect of helical nozzles gap on the cooling capacity of Ranque-Hilsch vortex tube. International Journal of Refrigeration, 35(5), 14731483.

[27] Van Deemter, J. J. (1952). On the theory of the Ranque-Hilsch cooling effect. Applied Scientific Research, Section A, 3(3), 174-196.

[28] Borisenko, A. I., Safonov, V. A., Yakovlev, A. I. (1968). The effect of geometric parameters on the characteristics of a conical vortex cooling unit. Journal of Engineering Physics and Thermophysics, 15(6), 11581162 .

[29] R. A. Polisel, M. S. Rocha and J. R. Simões-Moreira, (2007). Parametric studies of a ranque-hilsch vortex tube, 19th International Congress of Mechanical Engineering, Brasilia.

[30] Y Wu, Y. T., Ding, Y., Ji, Y. B., Ma, C. F., \& Ge, M. C. (2007). Modification and experimental research on vortex tube. International Journal of Refrigeration, 30(6), 1042-1049.

[31] Valipour, M. S., Niazi, N. (2011). Experimental modeling of a curved Ranque-Hilsch vortex tube refrigerator. International Journal of Refrigeration, 34(4), 1109-1116.

[32] SNimbalkar, S. U., \& Muller, M. R. (2009). An experimental investigation of the optimum geometry for the cold end orifice of a vortex tube. Applied Thermal Engineering, 29(2-3), 509-514.

[33] Rafiee, S. E., Sadeghiazad, M. M. (2016). Experimental study and 3D CFD analysis on the optimization of throttle angle for a convergent vortex tube. Journal of Marine Science and Application, 15(4), 388-404.

[34] Herrada, M. A., Pérez-Saborid, M., \& Barrero, A. (1999). Thermal separation in near-axis boundary layers with intense swirl. Physics of Fluids, 11(12), 3678-3687.

[35] Takahama, H., Yokosawa, H. (1981). Energy separation in vortex tubes with a divergent chamber. Journal of Heat Transfer, 103(2), 196-203.

[36] Poshernev, N. V., \& Khodorkov, I. L. (2004). Natural-gas tests on a conical vortex tube (CVT) with external cooling. Chemical and Petroleum Engineering, 40(3-4), 212-217.

[37] Devade, K. D., Pise, A. T. (2017). Effect of Mach number, valve angle and length to diameter ratio on thermal performance in flow of air through Ranque Hilsch vortex tube. Heat and Mass Transfer, 53(1), 161-168.

[38] Bovand, M., Valipour, M. S., Dincer, K., \& Tamayol, A. (2014). Numerical analysis of the curvature effects on Ranque-Hilsch vortex tube refrigerators. Applied Thermal Engineering, 65(1-2), 176-183.

[39] Bovand, M., Valipour, M. S., Eiamsa-ard, S., \& Tamayol, A. (2014). Numerical analysis for curved vortex tube optimization. International Communications in Heat and Mass Transfer, 50, 98-107.

[40] Devade, K. D., Pise, A. T. (2012). Investigation of Refrigeration Effect Using Short Divergent Vortex Tube. International Journal of Earth sciences and engineering, 5(1), 378-384.

[41] Devade, K., Pise, A. (2014). Effect of cold orifice diameter and geometry of hot end valves on performance of converging type Ranque Hilsch vortex tube. Energy Procedia, 54, 642-653.

[42Guen, M., Natkaniec, C., Kammeyer, J., Seume, J. R., Adjlout, L., \& Imine, O. (2013). Effect of the conicalshape on the performance of vortex tube. Heat and Mass Transfer, 49(4), 521-531.

[43] Pouraria, H., Zangooee, M. R. (2012). Numerical investigation of vortex tube refrigerator with a divergent hot tube. Energy Procedia, 14, 1554-1559. 
[44] Marshall, J. (1977). Effect of operating conditions, physical size and fluid characteristics on the gas separation performance of a Linderstrom-Lang vortex tube. International Journal of Heat and Mass Transfer, 20(3), $227-231$. [45] Dyskin, L. M. (1989). Characteristics of a vortex tube with detwisting of cold flow. Journal of Engineering Physics and Thermophysics, 57(1), 756-758.

[46] Dincer, K., Baskaya, S., Uysal, B. Z., Ucgul, I. (2009). Experimental investigation of the performance of a Ranque-Hilsch vortex tube with regard to a plug located at the hot outlet. International Journal of Refrigeration, 32(1), 87-94.

[47] Dincer, K., Yilmaz, Y., Berber, A., Baskaya, S. (2011). Experimental investigation of performance of hot cascade type Ranque-Hilsch vortex tube and exergy analysis. International Journal of Refrigeration, 34(4), 11171124.

[48] Im, S. Y., Yu, S. S. (2012). Effects of geometric parameters on the separated air flow temperature of a vortex tube for design optimization. Energy, 37(1), 154-160.

[49] Rafiee, S. E., Sadeghiazad, M. M. (2016). Experimental study and 3D CFD analysis on the optimization of throttle angle for a convergent vortex tube. Journal of Marine Science and Application, 15(4), 388-404.

[50] Stephan, K., Lin, S., Durst, M., Huang, F., Seher, D. (1983). An investigation of energy separation in a vortex tube. International Journal of Heat and Mass Transfer, 26(3), 341-348. 